\title{
Applications of LA-ICP-MS in the elemental analyses of geological samples
}

\author{
LIU YongSheng ${ }^{*}$, HU ZhaoChu, LI Ming \& GAO Shan \\ State Key Laboratory of Geological Processes and Mineral Resources, China University of Geosciences, Wuhan 430074, China
}

Received January 26, 2013; accepted April 16, 2013; published online June 6, 2013

\begin{abstract}
Laser ablation-inductively coupled plasma-mass spectrometry (LA-ICP-MS), which is a rapidly developing analytical technique for the analyses of trace elements and isotopes, plays an important role in advancing the study of Earth science, especially with respect to micro-geochemistry. This article reviews the application of LA-ICP-MS in the elemental analysis of solid geological samples. Although LA-ICP-MS has been widely used in the spatial resolution analysis of element compositions and rapid bulk analysis of whole-rock and soil samples, the analysis accuracy is restricted by numerous factors, including the instrumental conditions, the elemental fractionation and matrix effects, the lack of sufficient matrix-matched reference materials, and the strategies for quantitative calibration and sensitivity drift correction. According to the type of samples and the analyte elements, the analysis accuracy can be improved through the optimization of instrument conditions and the adoption of suitable correction strategies and reference materials.
\end{abstract}

LA-ICP-MS, geological sample, elemental analysis, quantitative strategy

Citation: $\quad$ Liu Y S, Hu Z C, Li M, et al. Applications of LA-ICP-MS in the elemental analyses of geological samples. Chin Sci Bull, 2013, 58: 3863-3878, doi: $10.1007 / \mathrm{s} 11434-013-5901-4$

The in situ analyses of trace elements and isotope compositions of solid samples using methods that do not involve complex and time-consuming wet-chemical digestion is a key point that has been attracting the attention of chemists. The micro-analysis of elemental concentrations in solid samples has been an attractive frontier in the development of analytical science. Micro-geochemistry has recently been suggested to perhaps lead the development of geochemistry in the future. In 1984, soon after the first commercial ICPMS appeared, Gray [1] analyzed the elemental and $\mathrm{Pb}$ isotope compositions of granites by combining ICP-MS and LA, thereby introducing the micro-analytical technique of laser ablation-inductively coupled plasma-mass spectrometry (LA-ICP-MS). Jackson et al. [2] fully demonstrated the strong potential of LA-ICP-MS in analyzing the trace-element compositions of geological samples, and LA-ICP-MS were subsequently used to measure the partition coefficients of the trace elements [3]. Fryer et al. [4] were the first to

\footnotetext{
*Corresponding author (email: yshliu@ @ug.edu.cn)
}

adopt LA-ICP-MS to the in situ analysis of the U-Pb geochronology of U-rich minerals. Li et al. [5] developed a method to simultaneously conduct $\mathrm{U}-\mathrm{Pb}$ dating and traceelement analysis for a single zircon grain using LA-ICP-MS. In recent years, the technique of in situ analysis of trace elements and isotopes using LA-ICP-MS has been quickly developed and widely used in numerous fields, including geology, metallurgy, environmental science, biology, chemistry, materials science and archeology (Figure 1).

The fundamental operating principle of LA-ICP-MS is that a laser beam is focused onto the surface of a sample contained in an ablation cell, the sample is ablated and gasified and is then carried, as particulates (i.e. an aerosol), by the carrier gas (He or/and Ar) into the ICP to be ionized; after ionization, the ions with different mass-to-charge ratios are then filtered by the mass spectrum system and are detected by the detector. Compared with solution nebulization (SN)-ICP-MS, LA-ICP-MS has the advantages of greater spatial resolution (typically greater than $5 \mu \mathrm{m}$ for profile analysis and $n \times 100 \mathrm{~nm}$ for depth analysis), lower 


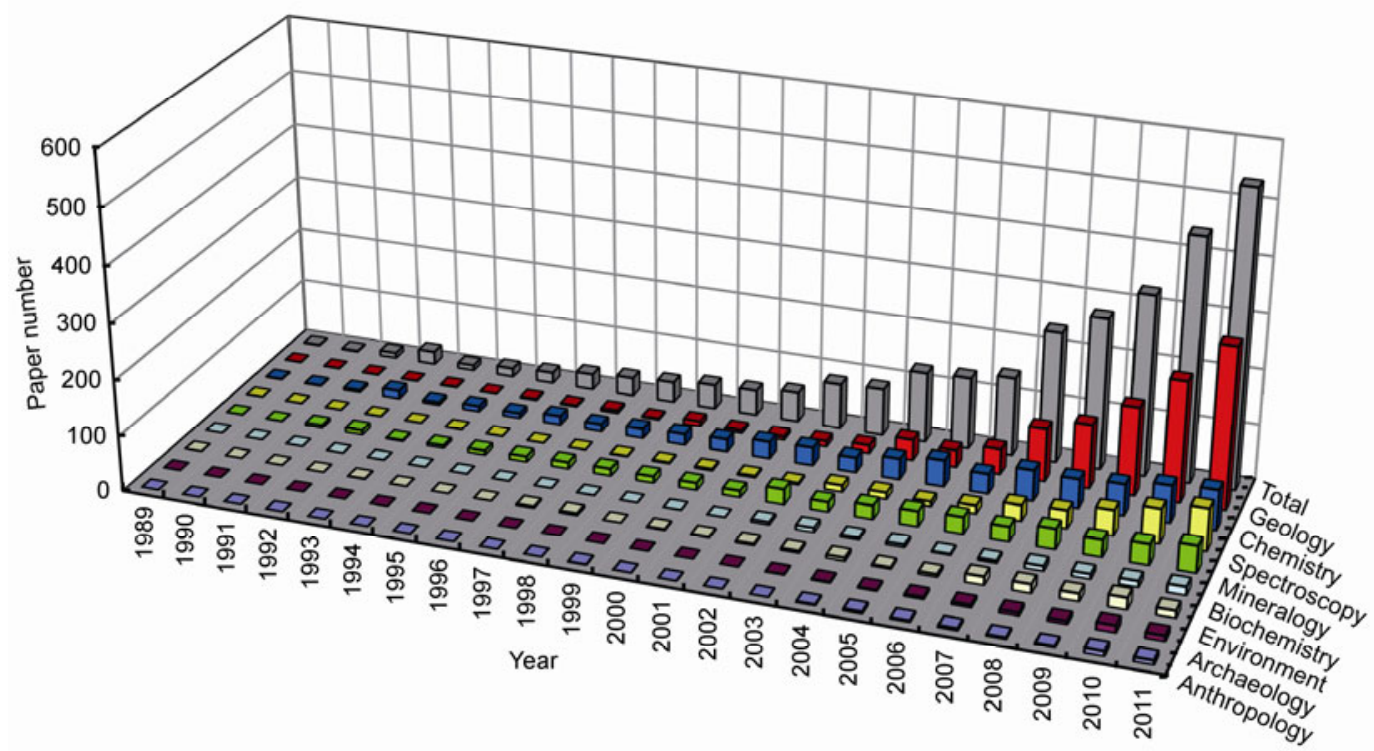

Figure 1 The application of LA-ICP-MS in different academic fields over the past 20 years. The data were extracted from the Web of Science.

sample consumption, faster and more efficient (less than 3 min for a single-point analysis), a lower background and fewer interferences from oxides and hydroxides [6]. Furthermore, the use of LA-ICP-MS avoids the time-consuming sample digestion process and sample-digestion-related problems (e.g. incomplete digestion of some minerals and poor stability of some elements in dilute acid solutions) faced by SN-ICP-MS [7,8]. As a consequence, LA-ICP-MS has been used in the geosciences not only as a single-spot analysis method, especially where trace element or isotope concentrations are required at high spatial resolution (e.g. the analysis of a single fluid/melt inclusion, a single zircon grain, or the zonation of a mineral) [2,4,5,9-16] or distribution analyses of elements and isotopes of rocks and minerals are required [17-21], but also for bulk analyses of rocks and soils [22-29].

Several factors affect the accuracy of an analysis of elemental content; these factors primarily include the instrumental conditions (i.e. the wavelength and pulse width of the laser and the sensitivity and resolution of ICP-MS), the quantitative calibration strategy, the standards used for calibration, the matrix and fractionation effects, and the sensitivity drift of the instrument. With the application of a suitable calibration strategy and optimized instrument conditions, better precision (better than 5\%) and accuracy (better than 5\%-10\%) could be obtained using LA-ICP-MS analysis compared to that achieved using SN-ICP-MS. Many early LA-ICP-MS systems utilized the fundamental infrared wavelength of $\mathrm{Nd}$ :YAG lasers $(1064 \mathrm{~nm})$, which is poorly absorbed by many rock-forming minerals. The application of a UV laser in LA-ICP-MS systems resulted in significant improvements in the spatial resolution, better material absorptivity, reduced elemental fractionation and improved analytical precision. The use of shorter-wavelength lasers
[30] (i.e. the replacement of $1064 \mathrm{~nm}$ wavelength with 266 $\mathrm{nm}$ ) (frequency-quadrupled output) or $213 \mathrm{~nm}$ (frequencyquintupled output) wavelength harmonic generators [31] or the use of $157 \mathrm{~nm} \mathrm{[32]} \mathrm{or} 193 \mathrm{~nm}$ [33] wavelengths produced by excimer gas lasers) and shorter pulse (e.g. femtosecond lasers) [34] can produce aerosols with smaller particle sizes and thereby reduce the non-stoichiometric effect. The shortcomings of $157 \mathrm{~nm}$ laser irradiation, which include the strong absorptivity of this wavelength by oxygen and its inherently low energy, have restricted its wide use. The properties of the 213 and $193 \mathrm{~nm}$ wavelengths with respect to the previously mentioned characteristics, are better than those of the $266 \mathrm{~nm}$ wavelength [35,36] and have thus been used more widely in laser ablation systems. Compared to nanosecond-laser ablation systems, the femtosecond-laser ablation systems provide significantly improved analytical performance, including a stronger signal intensity for a similar fluence, reduced matrix effects, better particle-size distributions, and negligible thermally induced fractionation; the femtosecond-laser systems are thus regarded as a more versatile analytical technique [34,37,38].

In addition to the instrumental hardware, other critical factors that affect analyses, including the choice of suitable reference materials and a calibration strategy for quantification, the optimization of instrumental parameters, the adaptation of reasonable correction strategies for sensitivity drift, and elemental fractionation, need to be taken into consideration for obtaining accurate analysis data via LA-ICP-MS.

\section{Quantitative calibration of elemental contents analyzed by LA-ICP-MS}

When LA-ICP-MS is used to perform quantitative analysis, 
the method of combining external calibration and internal normalization is generally used [39], as demonstrated in eq. (1),

$$
\left\{\begin{array}{l}
C_{\mathrm{sam}}^{i}=\left(c p s_{\mathrm{sam}}^{i} \times l^{i}\right) \times k_{i s}, \\
l^{i}=C_{\mathrm{rm}}^{i} / c p s_{\mathrm{rm}}^{i}, \\
k_{i s}=\left(c p s_{\mathrm{rm}}^{i s} / C_{\mathrm{rm}}^{i s}\right) /\left(c p s_{\mathrm{sam}}^{i s} / C_{\mathrm{sam}}^{i s}\right),
\end{array}\right.
$$

where $C_{\mathrm{sam}}^{i}$ is the concentration of analyte element $i$ in the sample, $C_{\mathrm{rm}}^{i}$ is the concentration of analyte element $i$ in the reference material for calibration, $c p s_{\mathrm{sam}}^{i}$ is the net count rate (sample signal minus background) of $i$ in the sample, $c p s_{\mathrm{rm}}^{i}$ is the net count rate of $i$ in the reference material for calibration, $c p s_{\text {sam }}^{i s}$ is the net count rate of internal standard element $i s$ in the sample, $c p s_{\mathrm{rm}}^{i s}$ is the net count rate of $i s$ in the reference material for calibration, $C_{\text {sam }}^{i s}$ is the concentration of $i s$ in the sample, and $C_{\mathrm{rm}}^{i s}$ is the concentration of $i s$ in the reference material for calibration. The concentration of the internal standard element (regularly refer to one major element) must be obtained using other independent approaches (e.g. measured using EMP or calculated according to the stoichiometric formula). The use of the fixed stoichiometric formula method may introduce extra error if the internal standard element is heterogeneous in the sample, whereas the adoption of other independent ways of measuring the internal standard element can increase costs and workload. Moreover, diverse analytical results can be obtained when different elements are used as the internal standard [40]; the concentration of the analyte element can only be accurately measured when the internal standard element and the analyte element behave similarly during ablation. Different fractionation effects of the internal standard element and the analyte element are key factors that limit accurate calibration with this method. Jackson [41] found that, in general, a linear correlation exists between the fractionation index (FI) and the achieved accuracy when non-matrix-matched calibration is used; the FI therefore provides a simple means of correcting fractionation-related errors. Based on the linear relationship between accuracy and FI, Jackson [41] suggested a multiple internal standard correction procedure, as shown in the following equation:

$$
C_{\mathrm{Sam}_{\mathrm{CORR}}}^{i}=C_{\mathrm{Sam}_{i s 1}^{i}}^{i}-\left(C_{\mathrm{Sam}_{i s 1}^{i}}^{i}-C_{\mathrm{Sam}_{i s 2}}^{i}\right) \times \frac{\mathrm{FI}^{i}-\mathrm{FI}^{i s 1}}{\mathrm{FI}^{i s 2}-\mathrm{FI}^{i s 1}},
$$

where $C_{\text {Sam }_{\text {CORR }}}^{i}$ is the corrected concentration of analyte element $i$ in the sample; $C_{\mathrm{Sam}_{i s 1}}^{i}$ is the concentration of analyte element $i$ in the sample determined using internal standard is $1 ; C_{\mathrm{Sam}_{\text {is } 2}}^{i}$ is the concentration of analyte element $i$ in the sample determined using internal standard $i s 2$;
$\mathrm{FI}^{i}$ is the fractionation index of analyte element $i$; $\mathrm{FI}^{i s 1}$ is the fractionation index of internal standard element is 1 ; and $\mathrm{FI}^{i s 2}$ is the fractionation index of internal standard element $i s 2$. The advantages of this procedure are that it is not predicated on near-linear analyte/internal standard intensity ratios and that it relies on data for major elements, which are generally homogenously distributed within geological samples and can be measured accurately. Therefore, the accuracy of the analytical result can generally be enhanced when this method is used. The disadvantages are that the method requires accurate information on two or more major elements (i.e. those used as internal standards) and that the FIs of these major elements must differ greatly. A larger error will be generated as error propagation if the difference in the FI between the major elements used as internal standards is small.

Leach and Hieftje [42] explored a summed-spectrum normalization calibration procedure to determine elements in alloys using LAICP-MS without applying internal standardization. Although this technique is most likely feasible for alloys, it is not practical for silicate minerals with a variable matrix. Irrespective of the outcome of the sum normalization calibration procedure, the work of Leach and Hieftje [42] rekindled an interest in major- and traceelement analyses of solid materials using LA-ICP-MS without internal standardization. As an improvement to the summed signal normalization technique, Halicz and Günther [43] calculated the concentration of the internal standard based on normalization of the sum of all metal oxides to $100 \mathrm{wt}$ \% to determine the trace-element compositions of anhydrous silicates. This method has been used to analyze the major and trace elements of silicate glasses $[40,43,44]$, silicate minerals $[40,45,46]$, carbonate minerals [47], silicate whole-rocks [23,24] and metal oxides [48]. The generic formula for this calibration method is demonstrated as follows:

$$
\left\{\begin{array}{l}
C_{\mathrm{sam}}^{i}=\left(c p s_{\mathrm{sam}}^{i} \times l^{i}\right) \times k_{\mathrm{total}} \\
l^{i}=\sum_{s=1}^{n}\left(\left(C_{\mathrm{rm}^{s}}^{i} / c p s_{\mathrm{rm}^{s}}^{i}\right) \times\left(C_{\mathrm{rm}^{s}}^{i} / \sum_{s=1}^{n} C_{\mathrm{rm}^{s}}^{i}\right)\right) \\
k_{\mathrm{total}}=\left(100-C_{\mathrm{sam}}^{v}\right) / \sum_{j=1}^{N}\left(c p s_{\mathrm{sam}}^{j} \times l^{j}\right)
\end{array}\right.
$$

where $c p s_{\text {sam }}^{i}\left(c p s_{\text {sam }}^{j}\right)$ is the net signal intensity of analyte element $i(j)$ in the sample; $c p s_{\mathrm{rm}^{s}}^{i}$ is the net signal intensity of analyte element $i(j)$ in the reference material $s$ for calibration; $C_{\mathrm{sam}}^{i}$ (and $C_{\mathrm{rm}^{s}}^{i}$ ) is the concentration of analyte element $i$ (in the form of a simple substance for the analysis of metals and/or alloys [49], in the form of an oxide for the analysis of silicate minerals and glasses [40], in the form of a carbonate for the analysis of carbonate minerals [47] or in the form of a sulfide for the analysis of sulfide minerals) in the sample (and reference material $s$ ); $C_{\text {sam }}^{v}$ is the content 
of the unmeasured volatile component or complex anion in the sample; $n$ is the number of reference materials used for calibration, $N$ is the number of elements that can be measured by LA-ICP-MS (elements should be analyzed as many as possible). The essence of the summed component normalization technique is to calculate the concentration of the analyte element using all components in the sample as internal standards. When a single external standard is used, the slope $\left(l^{i}\right)$ of the calibration curve is the same as that in eq. (1); when multiple external standards are used, the slope $\left(l^{i}\right)$ of the calibration curve can be calculated based on the concentration-weighted average, which leads to the greatest reduction in uncertainty introduced through the relatively high uncertainties of those elements with low concentrations in the reference materials [40] because, for a given element, high concentrations can be determined more precisely than low concentrations, and the reference values of high concentrations are typically more accurate than those of low concentrations.

Isotopic dilution method, which avoids the use of external standards, can also be adopted to analyze bulk rock and soil samples via LA-ICP-MS [50]. In some special cases, meaningful results can be obtained through simple calibration against matrix-matched external standards. For example, McCandless et al. [51] analyzed the trace elements of individual fluid inclusion in quartz using a simple external calibration against artificially prepared fluid inclusions. Despite the low accuracy of the simple external calibration method, it is simple and effective to understand the variation or distribution of elements in a small solid sample when there is no matrix-matched reference material or internal standard available. For example, Butler and Nesbitt [52] adopted this method to investigate the distributions of trace elements in the chalcopyrite wall of a black smoker chimney.

\section{Factors affecting accurate elemental analysis with LA-ICP-MS}

The accuracy and precision of elemental analyses performed with LA-ICP-MS are limited by many factors, including the laser ablation conditions, the ICP-MS analytical conditions, instrumental sensitivity drift, matrix effects between the sample and standards, fractionation effects, the accuracy of the recommended values for reference materials used for calibration, and the internal standard used for normalization.

\subsection{Reference materials and matrix effects}

Reference materials play an important role in LA-ICP-MS analysis. They are used as samples for quantitative calibration, quality control and assurance, and the development of methods and for inter-laboratory comparisons of analysis data. A credible reference material is a prerequisite to the acquisition of accurate data with LA-ICP-MS. The refer- ence materials can be divided into four types: synthetic reference glasses, geological reference glasses with natural compositions, synthetic minerals and natural minerals [53].

Synthetic reference glasses consist mainly of the standard reference materials (SRM) of the 600 series (SRM 610-617) of the National Institute of Standards and Technology (NIST) and the GS reference glasses (GSC-1G, GSD-1G and GSE-1G) of the United States Geological Survey (USGS). The compositions of the NIST SRM 61x series differ from those of natural rocks and minerals; they contain 61 trace elements and four major elements $\left(\mathrm{SiO}_{2}, \mathrm{Al}_{2} \mathrm{O}_{3}\right.$, $\mathrm{CaO}$ and $\mathrm{Na}_{2} \mathrm{O}$ ) [54-57]. SRM 610 and SRM 612 are the most widely used NIST glasses. They have the advantages that the concentrations of all of the trace elements are similar and high (ca. 400-500 ppm for SRM 610 and 30-40 ppm for SRM 612). The USGS GS reference glasses have major element compositions of basalt and many trace elements in similar abundance at different concentrations (ca. 4-5 ppm for GSC-1G, ca. 40-50 ppm for GSD-1G and ca. 400-500 ppm for GSE-1G) [44,58]. Reference glasses with natural composition are produced by the direct melting of natural rocks and soil powders. They mainly include USGS reference glasses (BCR-2G, BHVO-2G and BIR-1G), MPIDING reference glasses (KL2-G, ML3B-G, StHs6/80-G, GOR128-G, GOR132-G, BM90/21-G, ATHO-G and T1-G) and Chinese Geological Standard Glasses (CGSG) (CGSG1, CGSG-2, CGSG-4 and CGSG-5). The USGS reference glasses have natural basaltic compositions [27,58-60], whereas the MPI-DING reference glasses comprise basalt (KL2-G and ML3B-G), andesite (StHs6/80-G), komatiite (GOR128-G, GOR132-G), peridotite (BM90/21-G), rhyolite (ATHO-G) and quartz diorite (T1-G) [61,62], and the CGSG reference glasses comprise basalt (CGSG-1), syenite (CGSG-2), andesite (CGSG-5) and soil (CGSG-4) [63].

Except for reference materials with silicate compositions, reference materials with compositions of sulfide, carbonate and phosphate are very limited. In-house reference materials of sulfide are typically used in most laboratories; these materials are synthesized by the following methods: (1) NiS fire assay $[14,64],(2)$ a welding technique at high temperature and high pressure [65-69] and (3) pressed powder pellets [70,71]. Gilbert et al. [72] evaluated the homogeneity of the PGE and $\mathrm{Au}$ in six sulfide-matrix reference materials (synthetic pyrrhotite 8b [73], Po724-T and Po727-T1 [74], fused nickel sulfides PGE-A [75] and NiS-3 [72], and Lombard iron meteorite [76]) and the consistency of concentrations against different reference materials via crosscalibration. They found that Po727-T1 and 8b produced results that were comparable, within uncertainty, for all elements. Po727-T1 also produced consistent results with NiS-3 for all elements. All other RMs showed differences for some elements, especially Ru in Po724-T and Os, Ir and $\mathrm{Au}$ in PGE-A. Po724-T, Po727-T1 and the Lombard meteorite were found to be homogeneous with respect to all elements; however, 8b, PGEA and NiS-3 were heterogene- 
ous with respect to only some elements. MASS-3 is a commercially available pressed-powder pellet of sulfide produced by the USGS for trace element analysis. The welding technique and pressed-powder pellets were generally used to develop reference materials with other special matrixes. Bédard et al. [77] developed a reference material for analyzing trace element concentrations in zircon by welding a mixture of zircon and albite powders. Klemme et al. [78] prepared 11 synthetic silicate and phosphate glasses to serve as reference materials for the in situ microanalysis of clinopyroxene, apatite, titanite and other phosphate and titanite phases. In addition, synthetic Ca-phosphate pellets MAPS-4 and MAPS-5 have been produced by USGS. Pressed-powder pellets of carbonate have been used in many laboratories as in-house reference materials for the analysis of samples with a carbonate matrix [79-83]. Calcium carbonate pressed pellets MACS-1, MACS-2 and MACS-3, which contain $>60$ trace elements with high concentrations, have been developed by the USGS.

Suitable reference materials and accurate knowledge of their compositions are necessary to achieve accurate analyses using LA-ICP-MS. NIST glasses SRM 610 and SRM 612 are mostly used as primary calibration standards because they contain many trace elements in high concentrations; furthermore, most of the trace elements are homogenously distributed [84]. Despite the many advantages of the NIST glasses, their compositions differ from those of natural minerals and rocks, and thus different fractionation effects from the MPI-DING and USGS silicate glasses are observed. The NIST glasses have been shown to not be suitable external standards for the correction of natural silicate minerals and glasses $[40,46,85,86]$. For example, the relative deviation of REE in zircon is as high as $20 \%$ when calibrated against SRM 610 when Si is used as an internal standard, whereas the analysis accuracy can be improved remarkably if $\mathrm{Zr}$ is used as an internal standard [46]. Without doubt, the deviation caused by matrix effects between the standard and sample can be reduced to some degree through optimization of the instrument conditions (e.g. an increase in the energy density of the laser) [87]. MPI-DING glasses and USGS glasses have been shown to exhibit similar relative sensitivities, and they showed no obvious matrix-related fractionation effect when a $193 \mathrm{~nm}$ laser [40] or a $213 \mathrm{~nm}$ laser [87] was used. The disadvantage of using a calibration standard with low concentrations of some elements (i.e. the uncertainties of recommended values and instrument counting may be large) could be overcome through the use of multiple external standards, as previously discussed. Our experiments indicate that calibration against these reference glasses with natural compositions results in accuracies for the analysis of silicate minerals or glasses typically better than $10 \%[40,46,88]$. Jochum et al. [85] have suggested that a matrix-matched external standard must be used for the accurate analysis of $\mathrm{Pb}$.

In addition, both the recommended (or reference) values and homogeneity of reference materials can significantly affect the analytical accuracy. Eggins and Shelley [84] found that 24 elements (Ag, As, Au, B, Bi, Cd, Cr, Cs, Mo, $\mathrm{Pb}, \mathrm{Re},(\mathrm{Rh}), \mathrm{Sb}, \mathrm{Se}, \mathrm{Te}, \mathrm{Tl}, \mathrm{W}, \mathrm{Cu}, \mathrm{Pt}, \mathrm{Cd}, \mathrm{Fe}$ and $\mathrm{Mn}$ ) are distributed heterogeneously in the NIST glasses, whereas Be, Mg, Sr, Ba, Sc, Y, REE, V, Zr, Hf, Nb, Ta, Th, U, Ga, $\mathrm{In}, \mathrm{Sn}, \mathrm{Co}, \mathrm{Ni}$ and $\mathrm{Zn}$ show no evidence of significant heterogeneity. Many researchers have adopted various methods to obtain the best possible estimate of the "true" values of trace elements in the NIST glasses [54-57,89-91]. The USGS and MPI-DING reference glasses with natural compositions have also been extensively analyzed by laboratories that used different techniques, and the preferred values typically have a high degree of confidence [27,58,60-62,90, 92-94]. However, research on the synthetic USGS GS series standard glasses [44,58] is insufficient, and the uncertainties of some reference values are high. Recently, Chen et al. [47] and Jochum et al. [95] revised the reference value of $\mathrm{Nb}$ in carbonate-pellet MACS-3 (the revised value is 53.4-53.8 ppm).

\subsection{Elemental fractionation in ablation, transport and excitation processes}

Many authors have reported results related to the non-representative sampling of laser ablation (or non-stoichiometric ablation) and temporal changes in elemental responses during laser ablation, both of which are commonly referred to as "elemental fractionation" and could severely affect the accuracy of quantification. Elemental fractionation can occur during the ablation process, the aerosol transport process or the excitation process in ICP [86,96-101]. The intensity of the fractionation effect caused by temporal changes in elemental responses during laser ablation can be measured by the fractionation index (FI): $\left(\mathrm{FI}^{i}=\frac{c p s_{\text {Secondhalf }}^{i} / c p s_{\text {Secondhalf }}^{n s}}{c p s_{\text {Firsthalf }}^{i} / c p s_{\text {Secondhalf }}^{n s}}\right)$ [102]. The classification of elements based on the FI roughly follows the Goldschmidt geochemical classification of elements [86,97,102]. Košler et al. [95] found that the formation of phases of different mineralogy and/or chemical composition from the original sample at the ablation site can result in elemental fractionation (non-stoichiometric sampling) in material delivered to an ICP-MS for quantitative analysis. For example, both larger spherical particles and agglomerates of smaller particles produced by the ablation of zircon $\left(\mathrm{ZrSiO}_{4}\right)$ are mixtures of amorphous and crystalline materials-most likely zircon, baddeleyite $\left(\mathrm{ZrO}_{2}\right)$ and $\mathrm{SiO}_{2}$. $\mathrm{U}$ and Th are highly compatible with the structure of $\mathrm{ZrO}_{2}$ (baddeleyite) and $\mathrm{ZrSiO}_{4}$, whereas $\mathrm{Pb}$ is normally not present in large quantities, and significant quantities of the $\mathrm{Pb}$ would be excluded from either $\mathrm{ZrO}_{2}$ or from the thermally affected $\mathrm{ZrSiO}_{4}$. The difference in the transport efficiencies of the $\mathrm{ZrO}_{2}$ and $\mathrm{ZrSiO}_{4}$ particles and that of $\mathrm{Pb}$ and the degree of gasifica- 
tion and ionization of two types of particles may be the critical reason for the elemental fractionation of $\mathrm{Pb}$ and $\mathrm{U}$ [100]. Míková et al. [98] found that the fractionation trends of the alkali elements are different from those of other lithophile elements and that a combination of thermally driven diffusion and size-dependent particle fractionation are responsible for the observed fractionation of alkali elements during laser ablation of silicate samples. Kuhn and Günther [103] and $\mathrm{Hu}$ et al. [104] found that the trace-element patterns of aerosols vary significantly with particle size; for example, small aerosol particles are rich in chalcophile elements (i.e. $\mathrm{Cu}, \mathrm{Zn}, \mathrm{Ag}, \mathrm{Cd}, \mathrm{Sn}, \mathrm{Sb}, \mathrm{Pb}$ and $\mathrm{Bi}$ ). Moreover, the particlesize-related fractionation effects are different for aerosols ablated by a $266 \mathrm{~nm}$ laser and those ablated by a $193 \mathrm{~nm}$ laser. REE and HFSE tend to be enriched in the smaller aerosol particles when a $266 \mathrm{~nm}$ laser is used [103]; however, they tend to be enriched in the larger aerosol particles when a $193 \mathrm{~nm}$ laser is used [104].

Researchers can reduce or suppress the influence of the fractionation effect on the analysis accuracy by changing the laser system, optimizing the instrument conditions and applying a suitable data-reduction strategy. Ablation using a laser with a shorter wavelength or shorter pulse (e.g. using femtosecond instead of nanosecond laser pulses) could diminish the fractionation effect due to reduced thermal alteration of the sample material [105]. Guillong et al. [35] demonstrated that ablating silicate glass using a laser with a shorter wavelength could produce smaller particles and thus reduce elemental fractionation by comparing laser ablation using wavelengths of 266, 213 or $193 \mathrm{~nm}$. Günther and Heinrich [96] suggested that elemental fractionation was insignificant $(<10 \%)$ when a $193 \mathrm{~nm}$ laser was used. Shorter laser pulses result in weaker thermal effects of laser ablation and a thinner heated layer in the ablation pit. A femtosecond laser is not only predominantly non-thermal and causes less collateral damage than a laser with longer pulses, but it also provides smaller particle sizes for aerosols and no laserplasma interactions and has the potential to eliminate fractionation effects and matrix dependence [34]. The fractionation effect could also be diminished through optimization of the volume and geometry of an ablation cell to improve the efficiency and stability of aerosol transportation and to decrease the particle sizes and their distribution [104,106-108].

Elemental fractionation can also be reduced through optimization of the instrumental conditions. Mank and Mason [109] showed that large-diameter craters, if ablated with sufficient laser energy density, reduce elemental fractionation and give a more intense signal for a longer period of time. The carrier gas is a key factor that affects elemental fractionation. Using helium instead of argon as a carrier gas leads to smaller fractionation effects in silicate matrices and to a 2- to 4-fold signal enhancement when $193 \mathrm{~nm}$ lasers are used $[101,110]$. The purity of the carrier gas used in LAICP-MS as well as the amount of oxygen released from silicate and oxide samples during the ablation in an "oxy- gen-free" ambient gas were shown to contribute significantly to elemental fractionation [111]. Hirata [112] used a chemically assisted laser ablation technique (a Freon $\mathrm{R}-134 \mathrm{a}$ gas was introduced into the ablation cell as a fluorination reactant) to minimize the elemental fractionation. In addition, the energy density of the laser must be maintained at a sufficiently high and stable level; elemental fractionation in both ns- and fs-laser ablation systems can be reduced if the laser energy density exceeds the ablation threshold of the material being analyzed [113]. Furthermore, the ICP analytical conditions need to be optimized to achieve an improved degree of atomization and ionization (and thus a reduction in the degree of elemental fractionation), which can be monitored by the $\mathrm{U}^{+} / \mathrm{Th}^{+}$signal ratio in SRM 610 glass [105]. Both ions have similar ionization energies and masses, and both of their major isotopes have a relative abundance of $>99 \%$. If full atomization is achieved, an intensity ratio close to the concentration ratio in the ablated material can be expected.

To reduce the influence of elemental fractionation on the analysis accuracy, Sylvester and Ghaderi [15] suggested an 'intercept' method to calculate the ratio between the signal intensity for each isotope of interest and that of an internal standard element $\left(c^{i} s^{i} /\right.$ ps $\left.^{i s}\right)$ by linear fitting under the assumptions that the intrinsic value for $\operatorname{cps}^{i} / \mathrm{cps}^{i s}$ in an analyzed material is that measured at the start of laser ablation and that all subsequent measured ratios are progressively fractionated. In addition, the adoption of matrix-matched calibration standards and the selection of the same signal integration intervals for reference materials and unknown samples are important to reduce the influence of elemental fractionation on the accuracy of quantification.

\subsection{Laser ablation conditions}

The laser ablation conditions include the ablated spot size $(D)$, the laser frequency $(F)$, the energy density $(\mathrm{Ed})$, the laser ablation mode and the carrier gas. The spot size can not only affect sensitivity and elemental fractionation but also the matrix effects, depending on the mass load of the ICP [23]. For a given sample and energy density, if the average laser ablation rate ( $r$, measured by the sample depth ablated by a single laser pulse) is relatively stable, then the average volume of sample ablated per unit time $(V)$ is approximately dependent on the spot size (i.e. $V=F \times r \times$ $\left.\pi \times(D / 2)^{2}\right)$. Therefore, the sensitivity should show an exponential relationship with the diameter of the laser beam spot. The use of a relatively larger spot size can generally not only improve the accuracy and precision of the analysis, but can also reduce the detection limit. Moreover, a larger spot size increases the diameter/depth ratio of the ablation pit and thus reduces elemental fractionation [86,109]. However, the use of an excessively large spot size may enhance the mass-load-induced matrix effects in the ICP and the elemental fractionation because the amount of dry aerosol in- 
troduced into the ICP will increase significantly (depending on the laser energy density) [114,115] and thus hamper the accurate determination of some elements [23]. Spatialresolved analysis using a laser beam spot as small as possible is necessary for solving many problems in Earth science [116]. The use of a small laser beam spot can avoid the matrix effects that depend on the mass load of the ICP, but it will increase the analytical detection limits and require greater sensitivity of the ICP-MS instrumentation. Although accurate analysis data can be obtained through optimization of the instrument conditions when a small laser beam spot is used [116,117], the use of an excessively small laser beam spot (such as $<24 \mu \mathrm{m}$ ) could cause severe fractionation effects and thereby hinder the analysis via LA- ICP-MS [86].

The ablation rates vary with the sample matrix and are roughly positively correlated with the energy density for a given mineral/glass as a whole [110] (Figure 2). At a given energy density, the ablation rates of NIST glasses are significantly greater than that of the silicate minerals (e.g. zircon, olivine and garnet) and glasses with natural compositions. For example, the average ablation rates of NIST glasses are greater than that of zircon by a factor of approximately $50 \%$. Experiments have shown that the linear correlations between the sensitivity and F, as previously discussed, was not observed during the analysis of zircons [116], which implies that the ablation rate and/or spot size for each single pulse could vary with an increase in the ablation depth. The adoption of a lower pulse frequency can reduce the elemental fractionation by increasing the diameter/depth ratio of the ablation pit; however, some measures (e.g. the addition of a small amount of $\mathrm{N}_{2}$ ) should be taken to compensate for the reduced sensitivity [116]. Gaboardi and Humayun [87] suggested that the volatility effects (especially for transparent minerals or glasses) could be minimized and possibly negated by an increase in the laser energy output. However, Horn and Günther [110] showed that, as the energy density is increased, the particle size distribution

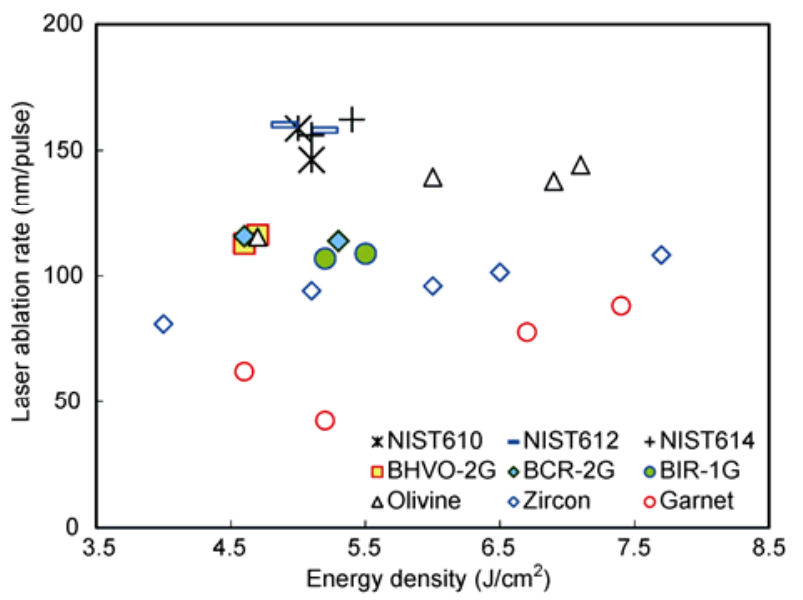

Figure 2 Variations of the ablation rates with the energy density using a $193 \mathrm{~nm}$ laser. shifts towards larger particles, at least for a Nd: YAG laser ablation system.

Although the type of carrier gas does not obviously affect the ablation rate [36], it can remarkably affect the particle size distribution, the transport efficiency and, thus, the sensitivity when a $193 \mathrm{~nm}$ laser is used [101,118]. The use of helium instead of argon as a carrier gas led to a 2- to 4-fold signal enhancement with $193 \mathrm{~nm}$ lasers [101,110,118]. Horn and Günther [110] showed that the ablation carrier gas strongly influences the particle size distribution when a 193 $\mathrm{nm}$ laser is used, whereas this effect is far less pronounced for ablations where a $266 \mathrm{~nm}$ laser is used. Their experiments also show that a $266 \mathrm{~nm}$ laser produces a larger proportion of primary particles that are not significantly influenced by the ablation carrier gas environment, whereas a $193 \mathrm{~nm}$ laser produces a larger proportion of vapor during irradiation with the $193 \mathrm{~nm}$ laser beam, and this vapor subsequently condenses to form larger aggregates [110]. The addition of a small amount of $\mathrm{N}_{2}$ or $\mathrm{H}_{2}$ into the carrier gas can increase the sensitivity and reduce the background and polyatomic ion yield [119-121]. Hu et al. [120] found that the addition of $5-10 \mathrm{~mL} \mathrm{~min}^{-1}$ of nitrogen into the central channel gas during LA-ICP-MS analyses increases the sensitivity for most of the 65 investigated elements by a factor of $2-3$.

The single-point mode and the line-scanning mode are generally used in LA-ICP-MS analyses. Laser ablation in the line-scanning mode is generally understood to produce a more stable signal and thus improve the analytical precision; in addition, it also provides a more representative sampling due to the larger area ablated compared with the area ablated during spot analysis [23]. However, material ablated in scanning mode is confined to the surface of the sample and has been shown to produce larger particles than spot ablations, which may result in more pronounced matrix effects, significant element fractionation due to incomplete ionization [99] and, thus, larger relative deviations for some elements [23].

\subsection{Sensitivity drift correction and internal standards}

Sensitivity drift in LA-ICP-MS analysis is one of the most important factors that influences the uncertainty of an analysis [122]. Sensitivity drift can be caused during laser ablation and ICP-MS analysis processes. Internal normalization is a classic method for correcting the ICP-MS sensitivity drift. However, the sensitivity drift is usually non-linear, the degree of drift differs from one mass to the next [123], and the drift rates are mass-dependent $[40,124]$; i.e. it is impossible to correct the sensitivity drift of all other elements using any single element (or isotope) as the internal standard. Therefore, Eggins et al. [124] developed a method that combines enriched isotopes and conventional elemental internal standards to precisely analyze trace elements by 
ICP-MS. The use of enriched isotopes expands the suite of available reference isotopes spaced through the mass spectrum so that the complex mass-dependent variations in sensitivity encountered during ICP-MS analysis can be monitored and corrected. However, this method is not applicable for the analysis of natural solid samples (such as natural minerals) via LA-ICP-MS. Gaboardi and Humayun [87] found that the elemental relative sensitivity shows an additional dependence on the temperature of condensation for the NIST glasses in addition to the dependences on the element mass and the first ionization potential. Therefore, with the use of NIST glasses as external calibration standards, analytical results for natural minerals or glasses could vary significantly based on the selection of different internal standard elements [40,41]. Successful matrix-independent standardization of refractory elements is possible if the condensing temperature of the internal standard element is approximately the same as that of the analyte element (such as the case with $\mathrm{Ca}$ and REE) [87]. The difference caused by the use of different major elements as internal standards can be measured by the variations in the $k$ values in eqs. (1) and (3) [40] (Figure 3).

Cheatham et al. [123] developed an analytical procedure and an off-line data reduction algorithm to correct the nonlinear sensitivity drift during SN-ICP-MS analyses, and this procedure resulted in a significant improvement in analytical accuracy and precision. In this technique, a "drift correction" standard is analyzed after every four or five samples. A polynomial curve is fitted for each isotope analyzed, and a correction based on this curve is applied to the measured intensity of the respective isotopes in the samples and standards. Eggins et al. [10], Sinclair et al. [125] and Liu et al. [40] combined this method and the internal standard normalization to correct the sensitivity drift during LA-ICPMS analysis, where they analyzed the "drift correction" standard SRM 610 after every 5-10 samples (i.e. SRM 610

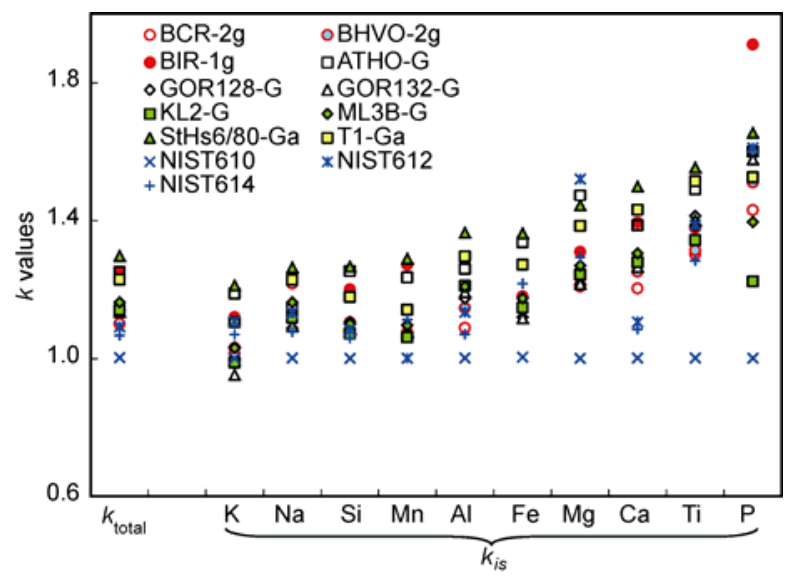

Figure 3 The $k$ values calculated using the internal standardization (eq. (1)) and summed metal oxide normalization techniques when SRM 610 was used as an external standard.
+ 5-10 samples + SRM 610) and then used the variations in the signal intensities [10] or signals normalized to a major element (such as $\mathrm{Si}$ in a silicate mineral) [40] of SRM 610 to correct the sensitivity drift. The possible contributions of sample position and laser focusing or imaging to the variations in the measurements of a "drift correction" standard can be partially corrected through normalization to a major element [40].

\section{Applications of LA-ICP-MS in the elemental analysis of geological samples}

\subsection{Bulk analyses of whole-rock and soil samples}

Compared with SN-ICP-MS for the bulk analysis of geological samples, LA-ICP-MS has several outstanding advantages, including a lower background, lower oxide and hydroxide interferences, a simpler sample preparation procedure, faster analyses, and cost effectiveness. Based on the sample preparation technique, LA-ICP-MS methods have been applied to the bulk analysis of various samples, including (1) the direct analysis of a rock slice [24,126], (2) the analysis of pressed-powder pellets both with binders $[1,26,127]$ and without binders [128], and (3) the analysis of fused glasses fused both with a flux agent $[6,129,130]$ and without a flux agent [22,23,25,61,131-134].

The homogeneous distribution of major and trace elements in the sample to be analyzed is a fundamental requirement for bulk analysis using LA-ICP-MS because of the relatively small ablation spot used (generally $<160 \mu \mathrm{m}$ ). The direct analysis of a rock slice using LA-ICP-MS can only be performed on cryptocrystalline volcanic rock, volcanic glass or fine-grained pelite because of the selective ablation of different minerals [24]. The pressing of a powder pellet without binders simplified the sample preparation and avoided any undesirable dilution of the sample; however, the particle size of the samples needs to be sufficiently reduced (e.g. to $<1 \mu \mathrm{m}$ ) [128]. If the particle size of the sample powder is relatively large or if the pellet is not sufficiently compacted, selective ablation of different minerals, signal variations caused by powder outbreak during ablation and the incomplete vaporization of particles could result in poor precision and accuracy $[28,135]$. The addition of binders could result in the production of discs with greater mechanical stability than that of discs obtained by pressing the sample alone, and the use of such discs could reduce signal instability caused by powder outbreak ablation $[127,136]$. Furthermore, pellets prepared with vanillic acid as a binder exhibited the greatest optical absorbance at a wavelength of $213 \mathrm{~nm}$, which resulted in a lower ablation depth and in improved signal sensitivity, most likely through the formation of smaller particles during the ablation process [127]. The disadvantage of the addition of a chemical binder is that the dilution effect may lead to the concentration of some elements in pressed pellets being lower than the detection 
limit. Fused glass is generally more homogeneous than a pressed-powder pellet and is therefore preferable for laser ablation analysis. The addition of a properly chosen flux (e.g. $\mathrm{Li}_{2} \mathrm{~B}_{4} \mathrm{O}_{7}$ ) significantly lowers the temperatures required for fusion of the rock powder, thereby improving the homogeneity of the fused glass and reducing the loss of volatile elements during the melting process. However, the introduction of the flux agents not only dilutes the traceelement contents but also increases the backgrounds for some elements (e.g. B, Li and REE) [137]. A flux-free fusion technique involves the direct melting of the rock powders in an Ar environment into homogeneous glasses at $1300-1800^{\circ} \mathrm{C}$ using an iridium strip heater [22,25,133,134], a tungsten strip heater ( $\mathrm{Hf}$ and Ta pollution may exist) [132] or a molybdenum strip heater [23,138], which avoids the above problems caused by the flux agent. For high- $\mathrm{SiO}_{2}$ rocks, high-purity $\mathrm{MgO}$ needs to be added to reduce the melt viscosity and result in homogeneous glasses [134]. Although this method seems to be simple, the high melting temperature may result in a severe loss of volatile elements (e.g. $\mathrm{Pb})[22,25]$. To minimize the volatilization of elements during high-temperature melting, the sample can be melted in a sealed platinum capsule, although this method is inherently expensive and not suitable for routine analysis [131] or in a $\mathrm{BN}$ crucible, which may result in metal segregation caused by the reduction of $\mathrm{BN}$ and result in the loss of $\mathrm{Cr}$, $\mathrm{Ni}$ and $\mathrm{Cu}$ [23]. The loss of volatile elements could be suppressed through the use of a sandwich-like heater with a double-filament [139].

The quantitative calculations for bulk analyses can be performed using an external standard calibration and internal standard (or summed metal oxide) normalization technique or an isotopic dilution method. If internal standard normalization is used, the element used as an internal standard should be analyzed using other independent methods (e.g. XRF or wet chemical methods) or added into the powder sample during the preparation of the pressed pellet or whole-rock glass $[28,136]$. The bulk content of volatile components (such as $\mathrm{H}_{2} \mathrm{O}$ and $\mathrm{CO}_{2}$ ) in the sample should be accurately measured using other independent methods if the summed metal oxide normalization technique is used. With the isotopic dilution method, an isotopic spike can be added into the powdered sample during the preparation of the pressed pellet $[29,50,140]$ or whole-rock glass [133]; trace elements can then be accurately measured without the use of any external standard.

\subsection{Silicate and carbonate minerals}

The method for analyzing silicate minerals is similar to that for silicate whole rocks. The frequently used calibration strategies include (1) Calibration against reference glasses SRM 610 or SRM 612, combined with normalization using a single (or multiple) internal standard (typically $\mathrm{Ca}, \mathrm{Si}$ and $\mathrm{Mg}$ depending on the type of mineral) $[2,3,10,59,141]$ or the summed metal oxide normalization method [142]. This method has the advantage that most elements can be calibrated against only one reference glass (i.e. the workload is small); however, the special matrix of NIST glasses may impede the accurate analysis of some samples (e.g. zircon) [46]. (2) Calibration against (multiple) silicate reference glasses with natural compositions (e.g. the MPI-DING and USGS glasses) and the application of the summed metal oxide normalization or internal standardization method $[40,45]$. Through the use of the summed metal oxide normalization technique, we can not only accurately analyze the trace elements in silicate minerals but can also determine the major element concentrations with accuracies comparable to that provided by EMP analysis and even better than that provided by EMP analysis for some major components (such as $\mathrm{MnO}$ ) [45]. Nevertheless, several reference glasses need to be analyzed (i.e. the workload is greater) to reduce the effect caused by the low concentrations of some elements in some individual reference glasses [40]. (3) Calibration against liquid standards, combined with the summed major element oxide normalization and internal standardization methods, where the calibration solutions are introduced into the ICP using an Aridus liquid sample introduction system with aerosol desolvation [43]. However, the composition of the solution used for the calibration can lead to losses of some elements during the desolvation process in the Aridus or during aerosol transfer to the ICP, which has been demonstrated for $\mathrm{Cu}$ [43].

Unlike the silicate reference materials, significantly fewer reference materials with carbonate matrix can be used for analysis of carbonate minerals by LA-ICP-MS. At present, the commercially available carbonate reference material for LA-ICP-MS analysis is the Ca-carbonate pellet MACS-3 developed by Dr. Stephen Wilson at the USGS; the concentrations of more than 50 trace elements in this reference material are greater than $1 \mathrm{ppm}$. Given the influence of the matrix effect on the accuracy of quantifications, numerous researchers have performed a substantial amount of work in preparing carbonate-matrix reference materials, such as $\mathrm{CaSiO}_{3}$ glass synthesized from coral powder [125], Ca-Mg carbonate glass with a lithium tetraborate flux [79] and pressed pellets of carbonate powders [79-83]. In general, the production of a homogeneous pressed pellet of a carbonate powder is difficult; a few elements in MACS-3 are even slightly heterogeneous [47]. The combination of external standard calibration and internal standard (generally Ca) normalization is often used to quantitatively analyze trace elements in carbonate materials using LA-ICP-MS [81, 143-145]. Chen et al. [47] proposed a method that combines an external-standard (silicate glass) calibration with the total normalization technique to analyze the major and trace elements in carbonate minerals and biological crusts. This method is based on the bulk components in carbonate materials consisting entirely of carbonate forms $\left(\mathrm{M}_{2 / x} \mathrm{CO}_{3}\right.$, where $x$ is the ion valence of element M). Strnad et al. [145] and 
Chen et al. [47] reported that the analysis results of carbonate samples calibrated against silicate reference glasses and those of carbonate samples calibrated against reference carbonate pellets exhibited no significant difference. However, Jochum et al. [95] suggested that accurate results can be obtained through calibration against silicate reference glasses for large ion lithophile elements but that matrix-matched standard calibration may be required for chalcophile and siderophile elements.

\subsection{Metal oxides and metal sulfides}

Trace elements in metal oxides can, in general, be accurately analyzed by calibration against silicate reference glasses. $\mathrm{Xu}$ et al. [146] and Huelin et al. [147] analyzed the trace elements in Fe-Mn oxides calibrated against SRM 610 in combination with internal-standard normalization. Nadoll and Koenig [148] found that the results of some trace elements calibrated against silicate reference glasses (SRM 610 and GSE-1G) agree well with results analyzed by EMP and suggested that magnetite can be accurately analyzed using silicate reference glasses as an external standard. Donohue et al. [149] analyzed thirteen trace elements in ilmenite $\left(\mathrm{FeTiO}_{3}\right)$ megacrysts using LA-ICP-MS (calibrated against SRM 610 with Ti used as internal standard) and reported good agreement between the results determined by LA-ICP-MS and SN-ICP-MS for most elements, except in cases where megacrysts with a titano-magnetite exsolution phase were present. With calibration against SRM 610 and the use of $\mathrm{Ti}$ as an internal standard [150] or with the application of multiple standards (BCR-2G, BHVO-2G and BIR-1G) for calibration in combination with the summed metal oxide normalization technique [48], trace elements in rutiles can be accurately analyzed by LA-ICP-MS, and the results are comparable with the results of SIMS and/or EMP analyses.

Both synthetic sulfide reference materials and silicate reference glasses have been used as external calibration standards for the analysis of sulfides by LA-ICP-MS. Because the concentrations of noble-metal elements (such as $\mathrm{Os}, \mathrm{Ir}, \mathrm{Ru}, \mathrm{Rh}, \mathrm{Pt}, \mathrm{Pd}$, and $\mathrm{Au}$ ) in silicate reference glasses are, in general, very low and heterogeneous, synthetic sulfide reference materials were prepared for the analysis of noble-metal elements in sulfides [14,65,72,73,151,152]. With the exception of the noble metal elements, the trace elements in sulfides could be calibrated against pressedpowder pellets of sulfide (e.g. MASS-1 or MASS-3) [153], glasses of sulfide fused with a lithium borate flux $[68,154$, 155], silicate reference glasses [156,157] or multi-element standard solutions [158]. Košler et al. [111] found that a small amount of oxygen released from the sample during the laser ablation process can also affect the elemental fractionation. Therefore, the influence of such different matrixes on the analytical accuracy needs to be further evaluated in cases where trace elements in sulfide are calibrated against silicate reference glasses.

In general, the lack of matrix-matched homogeneous reference materials is a bottleneck for accurate analyses of trace elements and the evaluation of the reliability of LAICP-MS analysis data for metal oxides and sulfides.

\subsection{Individual melt inclusion and fluid inclusion}

Heinrich et al. [159] and Pettke et al. [160] systematically reviewed the influencing factors, the calibration methods, the accuracy and the detection limits for the analysis of single melt/fluid inclusion by LA-ICP-MS. Shepherd and Chenery [161] were the first to study the feasibility of analyzing element compositions of single fluid inclusions by LA-ICP-MS. Moissette et al. [162] proposed a calibration strategy for the analysis of single fluid inclusions based on the use of the synthetic fluid inclusion in halite as an external standard. Applying a simple external calibration method, Ghazi et al. [163] and McCandless et al. [51] analyzed the single fluid inclusions in halite and quartz calibrated against a standard solution sealed in a glass capillary. However, the internal pressures of the natural inclusions are different from that of the artificial ones, which can lead to different release rates of volatile substances when the inclusions are opened. The error caused by the different ablation yields cannot be corrected using a simple external calibration. Thus, Shepherd et al. [164] tried to analyze the single fluid inclusions by using artificial inclusions as external standards and $\mathrm{Cl}$ determined by cryo-SEM-EDS as an internal standard. In addition, the direct ablation of a fluid inclusion with a pit size similar to the diameter of an inclusion commonly leads to an explosion and the splashing of material onto the sample surface [162] and into the chamber, which increases the danger of selective loss of solid internal precipitates. Therefore, Günther et al. [11] adopted a stepwise opening procedure for complex polyphase inclusions. They first drilled a small hole $(4-10 \mu \mathrm{m}$ pit) for the partial release of liquid and vapor, then completely drilled out a pit that covered the entire inclusion. A high laser energy density needs to be used to analyze fluid inclusions in quartz due to the poor absorption of quartz at the wavelengths typically used in laser ablation. The quantification of trace element concentrations could be calibrated against the NIST reference glasses or standard solutions with $\mathrm{Na}$ (or $\mathrm{Cl}$ ) used as an internal standard calculated according to the salinity $[11,159]$. The total salinity was generally determined by microthermometric measurements of phase transitions from known phase diagrams via measurements of either the depression of the ice-melting temperature or the temperature of dissolution of $\mathrm{NaCl}$ crystals. The methods used to estimate the $\mathrm{Na}$ (or $\mathrm{Cl}$ ) content by salinity may affect the analysis accuracy of single fluid inclusions [160,165]. Allan et al. [166] demonstrated that precision and accuracy are insensitive to inclusion size and depth. Analytical precision in the determination of $\mathrm{K}, \mathrm{Rb}$, and 
Cs is typically better than $15 \% \mathrm{RSD}$, whereas that for the determination of $\mathrm{Li}, \mathrm{Mg}, \mathrm{Ca}, \mathrm{Sr}, \mathrm{Ba}, \mathrm{Mn}, \mathrm{Fe}, \mathrm{Cu}, \mathrm{Zn}$, and $\mathrm{Cl}$ are typically reproducible within $30 \% \mathrm{RSD}$. The analyses of most elements are accurate to within $15 \%$. The limits of detection vary widely according to the inclusion volume, but range from 1 to $100 \mathrm{ppm}$ for most elements [166]. In recent years, important progress has been made in the analyses of $\mathrm{S}, \mathrm{Cl}$ and $\mathrm{Br}$ in single fluid inclusions by LA-ICP-MS. Guillong et al. [13] developed a method to analyze the $\mathrm{S}$ content in individual fluid inclusions using scapolite as an external standard and found that the factor that affected the precision and accuracy was not interference, but rather S pollution from an unknown source. Seo et al. [167] and Leisen et al. [168] reported a method for the analysis of $\mathrm{Cl}$ and $\mathrm{Br}$ concentrations in single fluid inclusions that involves calibration against NIST glass and/or scapolite.

The technique of analyzing element compositions in single melt inclusions using LA-ICP-MS was first applied to glassy melt inclusions exposed at the surface [169-171]. The method was later applied to recrystallized silicate melt inclusions in minerals with simple chemical compositions, such as quartz and topaz [172,173], and then to the unexposed and recrystallized melt inclusions in chemically complex minerals, such as amphibole, olivine, pyroxene, plagioclase and apatite [12,174-179]. At present, two analysis strategies have been generally used to analyze multiphase silicate melt inclusions using LA-ICP-MS: (1) The inclusion can be first homogenized and quenched to a homogenous glass and then ablated using a spot size smaller than the inclusion. Element concentrations could be quantified using the same method as that used for silicate minerals, which have been previously described. However, the homogenization of silicate melt inclusions can often be rather difficult or impossible due to potential decrepitation or leakage of the silicate melt inclusions upon heating. In addition, both diffusive exchange of certain elements between the host and the silicate melt inclusion and, if the homogenization temperature is excessively high, possible partial melting of the host mineral might modify the composition of the inclusion [175]. Furthermore, a sulfide in an inclusion is difficult to quench into glass using a fast cooling rate. (2) Ablation of the entire silicate melt inclusion along with its host mineral and subsequent deconvolution of the mixed ablation signal can be used $[12,174,175]$. This approach offers a unique opportunity to analyze the bulk composition of the unexposed and recrystallized silicate melt inclusion without homogenization through heating and greatly increases the number of inclusions that can be analyzed in the same crystal. The disadvantage of this method is that the content of one element in the inclusion or the content ratio of one element between the host mineral and the inclusion should be obtained through another independent method of quantification.

\section{What should we do in the future?}

The technique of analyzing element concentrations with LA-ICP-MS has been widely and maturely applied to numerous geological samples. Given the research status and problems associated with elemental analysis using LA-ICPMS, the following work could be conducted in the future: (1) the development of matrix-matched reference materials for different minerals (especially for metal oxides and sulfides); (2) the elucidation of the formation mechanisms of matrix-dependent and time-dependent elemental fractionations and the development of methods to eliminate or improve these mechanisms; (3) the establishment of accurate analysis methods with a high spatial resolution for natural minerals; (4) the development of a quantitative calibration strategy for single melt/fluid inclusions in complex minerals; (5) the development of a common protocol for data reduction and reporting for scientists to be able to compare and interpret these data accurately; and (6) the expansion of the application areas of element analysis using LA-ICP-MS.

This work was supported by the National Natural Science Foundation of China (90914007and 41125013), 111 Plans of Ministry of Education (B07039), the MOST Special Funds of the State Key Laboratory of Geological Processes and Mineral Resources (MSFGPMR201303) and the Fundamental Research Funds for the Central Universities.

1 Gray A L. Solid sample introduction by laser ablation for inductively coupled plasma source-mass spectrometry. Analyst, 1985, 110: 551-556

2 Jackson S E, Longerich H P, Dunning G R, et al. The application of laser-ablation microprobe-inductively coupled plasma-mass spectrometry (LAM-ICP-MS) to in situ trace-element determinations in minerals. Can Mineral, 1992, 30: 1049-1064

3 Jenner G A, Foley S F, Jackson S E, et al. Determination of partition coefficients for trace elements in high pressure-temperature experimental run products by laser ablation microprobe-inductively coupled plasma-mass spectrometry (LAM-ICP-MS). Geochim Cosmochim Acta, 1993, 57: 5099-5103

4 Fryer B J, Jackson S E, Longerich H P. The application of laser ablation microprobe-inductively coupled plasma-mass spectrometry (LAM-ICP-MS) to in situ (U)-Pb geochronology. Chem Geol, 1993, 109: $1-8$

5 Li X H, Liang X R, Sun M, et al. Geochronology and geochemistry of single-grain zircons: Simultaneous in-situ analysis of $\mathrm{U}-\mathrm{Pb}$ age and trace elements by LAM-ICP-MS. Eur J Mineral, 2000, 12: 10151024

6 Eggins S M. Laser ablation ICP-MS analysis of geological materials prepared as lithium borate glasses. Geostand Geoanal Res, 2003, 27 : $147-162$

7 Münker $\mathrm{C}$. $\mathrm{Nb} / \mathrm{Ta}$ fractionation in a Cambrian arc/back arc system, New Zealand: Source constraints and application of refined ICPMS techniques. Chem Geol, 1998, 144: 23-45

8 Zhang W, Hu Z, Liu Y, et al. Reassessment of $\mathrm{HF} / \mathrm{HNO}_{3}$ decomposition capability in the high-pressure digestion of felsic rocks for multi-element determination by ICP-MS. Geostand Geoanal Res, 2012, 36: 271-289

9 Audétat A, Günther D, Heinrich C A. Formation of a magmatichydrothermal ore deposit: Insights with LA-ICP-MS analysis of fluid inclusions. Science, 1998, 279: 2091-2094

10 Eggins S M, Rudnick R L, McDonough W F. The composition of 
peridotites and their minerals: A laser-ablation ICP-MS study. Earth Planet Sci Lett, 1998, 154: 53-71

11 Günther D, Audétat A, Frischknecht R, et al. Quantitative analysis of major, minor and trace elements in fluid inclusions using laser ablation inductively coupled plasma mass spectrometry. J Anal At Spectrom, 1998, 13: 263-270

12 Halter W, Pettke T, Heinrich C. Laser-ablation ICP-MS analysis of silicate and sulfide melt inclusions in an andesitic complex I: Analytical approach and data evaluation. Contrib Mineral Petrol, 2004, 147: 385-396

13 Guillong M, Latkoczy C, Seo J H, et al. Determination of sulfur in fluid inclusions by laser ablation ICP-MS. J Anal At Spectrom, 2008, 23: $1581-1589$

14 Jarvis K E, Williams J G, Parry S J, et al. Quantitative-determination of the platinum-group elements and gold using NiS fire assay with laser ablation-inductively coupled plasma-mass spectrometry (LAICP-MS). Chem Geol, 1995, 124: 37-46

15 Sylvester P J, Ghaderi M. Trace element analysis of scheelite by excimer laser ablation-inductively coupled plasma-mass spectrometry (ELA-ICP-MS) using a synthetic silicate glass standard. Chem Geol, 1997, 141: 49-65

16 Yuan H L, Gao S, Liu X M, et al. Accurate U-Pb age and trace element determinations of zircon by laser ablation-inductively coupled plasma-mass spectrometry. Geostand Geoanal Res, 2004, 28: 353-370

17 Peng S, Hu Q, Ewing R P, et al. Quantitative 3-D elemental mapping by LA-ICP-MS of a basaltic clast from the Hanford 300 Area, Washington, USA. Environ Sci Technol, 2012, 46: 2025-2032

18 Rusk B, Koenig A, Lowers H. Visualizing trace element distribution in quartz using cathodoluminescence, electron microprobe, and laser ablation-inductively coupled plasma-mass spectrometry. Am Mineral, 2011, 96: 703-708

19 Ulrich T, Kamber B S, Jugo P J, et al. Imaging element-distribution patterns in minerals by laser ablation-Inductively coupled plasmamass spectrometry (LA-ICP-MS). Can Mineral, 2009, 47: 10011012

20 Novotný K, Kaiser J, Galiová M, et al. Mapping of different structures on large area of granite sample using laser-ablation based analytical techniques, an exploratory study. Spectrochim Acta Part B, 2008, 63: 1139-1144

21 Meurer W P, Claeson D T. Evolution of crystallizing interstitial liquid in an arc-related cumulate determined by LA ICP-MS mapping of a large amphibole oikocryst. J Petrol, 2002, 43: 607-629

22 Norman M D, Pearson N J, Sharma A, et al. Quantitative analysis of trace elements in geological materials by laser ablation ICPMS: Instrumental operating conditions and calibration values of NIST glasses. Geostand Newsl, 1996, 20: 247-261

23 Zhu L, Liu Y, Hu Z, et al. Simultaneous analysis of major and trace elements in fused volcanic rock powders by using a hermetic vessel heater and LA-ICP-MS. Geostand Geoanal Res, 2013, 37: 207-229

$24 \mathrm{Li} \mathrm{M}, \mathrm{Hu} \mathrm{Z}$, Gao S, et al. Direct quantitative determination of trace elements in fine-grained whole rocks by laser ablation-inductively coupled plasma-mass spectrometry. Geostand Geoanal Res, 2011, 35: 7-22

25 Stoll B, Jochum K P, Herwig K, et al. An automated iridium-strip heater for LA-ICP-MS bulk analysis of geological samples. Geostand Geoanal Res, 2008, 32: 5-26

26 Jarvis K E, Williams J G. Laser-ablation inductively-coupled plasma-mass spectrometry (LA-ICP-MS): A rapid technique for the direct, quantitative-determination of major, trace and rare-earth elements in geological samples. Chem Geol, 1993, 106: 251-262

27 Gao S, Liu X, Yuan H, et al. Determination of forty two major and trace elements in USGS and NIST SRM glasses by laser ablationnductively coupled plasma-mass spectrometry. Geostand Geoanal Res, 2002, 26: 181-196

28 Baker S A, Bi M, Aucelio R Q, et al. Analysis of soil and sediment samples by laser ablation inductively coupled plasma mass spectrometry. J Anal At Spectrom, 1999, 14: 19-26

29 Fernández B, Claverie F, Pécheyran C, et al. Solid-spiking isotope dilution laser ablation ICP-MS for the direct and simultaneous determination of trace elements in soils and sediments. J Anal At Spectrom, 2008, 23: 367-377

30 Günther D, Horn I, Hattendorf B. Recent trends and developments in laser ablation-ICP-mass spectrometry. Fresenius J Anal Chem, 2000, 368: 4-14

31 Jackson S E. The application of Nd: YAG lasers in LA-ICP-MS. In: Sylvester $\mathrm{P}$, ed. Laser-ablation-ICPMS in the Earth Sciences: Principles and Applications. Ontario: Mineralogical Association of Canada, 2001. 29-45

32 Telouk P, Rose-Koga E F, Albarede F. Preliminary results from a New $157 \mathrm{~nm}$ laser ablation ICP-MS Instrument: New opportunities in the analysis of solid samples. Geostand Geoanal Res, 2003, 27: 5-11

33 Günther D, Frischknecht R, Heinrich C A, et al. Capabilities of an Argon Fluoride $193 \mathrm{~nm}$ excimer laser for laser ablation inductively coupled plasma mass spectrometry microanalysis of geological materials. J Anal At Spectrom, 1997, 12: 939-944

34 Fernández B, Claverie F, Pécheyran C, et al. Direct analysis of solid samples by fs-LA-ICP-MS. Trends Anal Chem, 2007, 26: 951-966

35 Guillong M, Horn I, Günther D. A comparison of 266 nm, $213 \mathrm{~nm}$ and $193 \mathrm{~nm}$ produced from a single solid state Nd:YAG laser for laser ablation ICP-MS. J Anal At Spectrom, 2003, 18: 1224-1230

36 Horn I, Guillong M, Günther D. Wavelength dependant ablation rates for metals and silicate glasses using homogenized laser beam profiles-Implications for LA-ICP-MS. Appl Surf Sci, 2001, 182: 91-102

37 Koch J, Günther D. Femtosecond laser ablation inductively coupled plasma mass spectrometry: Achievements and remaining problems. Anal Bioanal Chem, 2007, 387: 149-153

38 Shaheen M E, Gagnon J E, Fryer B J. Femtosecond (fs) lasers coupled with modern ICP-MS instruments provide new and improved potential for in situ elemental and isotopic analyses in the geosciences. Chem Geol, 2012, 330-331: 260-273

39 Longerich H P, Jackson S E, Günther D. Laser ablation inductively coupled plasma mass spectrometric transient signal data acquisition and analyte concentration calculation. J Anal At Spectrom, 1996, 11: 899-904

40 Liu Y S, Hu Z C, Gao S, et al. In situ analysis of major and trace elements of anhydrous minerals by LA-ICP-MS without applying an internal standard. Chem Geol, 2008, 257: 34-43

41 Jackson S E. Calibration strategies for elemental analysis by LAICP-MS. In: Sylvester P, ed. Laser ablation ICP-MS in the earth sciences: Current practices and outstanding issues. Quebec: Mineralogical Association of Canada, 2008. 169-188

42 Leach A M, Hieftje G M. Standardless semiquantitative analysis of metals using single-shot laser ablation inductively coupled plasma time-of-flight mass spectrometry. Anal Chem, 2001, 73: 2959-2967

43 Halicz L, Günther D. Quantitative analysis of silicates using LA-ICP-MS with liquid calibration. J Anal At Spectrom, 2004, 19: 1539-1545

44 Guillong M, Hametner K, Reusser E, et al. Preliminary characterisation of new glass reference materials (GSA-1G, GSC-1G, GSD-1G and GSE-1G) by Laser Ablation-Inductively Coupled Plasma-Mass Spectrometry using $193 \mathrm{~nm}, 213 \mathrm{~nm}$ and $266 \mathrm{~nm}$ wavelengths. Geostand Geoanal Res, 2005, 29: 315-331

45 Humayun M, Davis F A, Hirschmann M M. Major element analysis of natural silicates by laser ablation ICP-MS. J Anal At Spectrom, 2010, 25: 998-1005

46 Liu Y S, Hu Z C, Zong K Q, et al. Reappraisement and refinement of zircon $\mathrm{U}-\mathrm{Pb}$ isotope and trace element analyses by LA-ICP-MS. Chin Sci Bull, 2010, 55: 1535-1546

47 Chen L, Liu Y, Hu Z, et al. Accurate determinations of fifty-four major and trace elements in carbonate by LA-ICP-MS using normalization strategy of bulk components as $100 \%$. Chem Geol, 2011, 284: 283-295

48 Gao C, Liu Y, Zong K, et al. Microgeochemistry of rutile and zircon in eclogites from the CCSD main hole: Implications for the fluid activity and thermo-history of the UHP metamorphism. Lithos, 2010, 
115: 51-64

49 Liang T, Hu Z C, Liu Y S, et al. Quantitative analysis of steel by laser ablation-inductively coupled plasma mass spectrometry without applying an internal standard (in Chinese). Metall Anal, 2010, 30: 1-8

50 Tibi M, Heumann K G. Isotope dilution mass spectrometry as a calibration method for the analysis of trace elements in powder samples by LA-ICP-MS. J Anal At Spectrom, 2003, 18: 1076-1081

51 McCandless $T$ E, Lajack D J, Ruiz J, et al. Trace element determination of single fluid inclusions in quartz by laser ablation ICP-MS. Geostand Geoanal Res, 1997, 21: 279-287

52 Butler I B, Nesbitt R W. Trace element distributions in the chalcopyrite wall of a black smoker chimney: Insights from laser ablation inductively coupled plasma mass spectrometry (LA-ICPMS). Earth Planet Sci Lett, 1999, 167: 335-345

53 Jochum K P, Stoll B. Reference materials for elemental and isotopic analyses by LA-(MC)-ICP-MS: Successes and outstanding needs. In: Sylvester P, ed. Laser Ablation ICP-MS in the Earth Sciences: Current Practices and Outstanding Issues. Quebec: Mineralogical Association of Canada, 2008. 147-168

54 Pearce N J G, Perkins W T, Westgate J A, et al. A compilation of new and published major and trace element data for NIST SRM 610 and NIST SRM 612 glass reference materials. Geostand Geoanal Res, 1997, 21: 115-144

55 Jochum K P, Weis U, Stoll B, et al. Determination of reference values for NIST SRM 610-617 glasses following ISO guidelines. Geostand Geoanal Res, 2011, 35: 397-429

56 Rocholl A, Dulski P, Raczek I. New ID-TIMS, ICP-MS and SIMS data on the trace element composition and homogeneity of NIST certified reference material SRM 610-611. Geostand Geoanal Res, 2000, 24: 261-274

57 Rocholl A B E, Simon K, Jochum K P, et al. Chemical characterisation of NIST silicate glass certified reference material SRM 610 by ICP-MS, TIMS, LIMS, SSMS, INAA, AAS and PIXE. Geostand Geoanal Res, 1997, 21: 101-114

58 Jochum K P, Willbold M, Raczek I, et al. Chemical characterisation of the USGS reference glasses GSA-1G, GSC-1G, GSD-1G, GSE-1G, BCR-2G, BHVO-2G and BIR-1G using EPMA, ID-TIMS, ID-ICP-MS and LA-ICP-MS. Geostand Geoanal Res, 2005, 29: 285-302

59 Norman M D, Griffin W L, Pearson N J, et al. Quantitative analysis of trace element abundances in glasses and minerals: A comparison of laser ablation inductively coupled plasma mass spectrometry, solution inductively coupled plasma mass spectrometry, proton microprobe and electron microprobe data. J Anal At Spectrom, 1998, 13: 477-482

60 Rocholl A. Major and trace element composition and homogeneity of microbeam reference material: Basalt glass USGS BCR-2G. Geostand Geoanal Res, 1998, 22: 33-45

61 Jochum K P, Dingwell D B, Rocholl A, et al. The preparation and preliminary characterisation of eight geological MPI-DING reference glasses for in-situ microanalysis. Geostand Geoanal Res, 2000, 24: $87-133$

62 Jochum K P, Stoll B, Herwig K, et al. MPI-DING reference glasses for in situ microanalysis: New reference values for element concentrations and isotope ratios. Geochem Geophys Geosyst, 2006, 7: doi:10.1029/2005GC001060

$63 \mathrm{Hu}$ M-Y, Fan X-T, Stoll B, et al. Preliminary characterisation of new reference materials for microanalysis: Chinese geological standard glasses CGSG-1, CGSG-2, CGSG-4 and CGSG-5. Geostand Geoanal Res, 2011, 35: 235-251

64 Shibuya E K, Sarkis J E S, Enzweiler J, et al. Determination of platinum group elements and gold in geological materials using an ultraviolet laser ablation high-resolution inductively coupled plasma mass spectrometric technique. J Anal At Spectrom, 1998, 13: 941944

65 Ballhaus C, Sylvester P. Noble metal enrichment processes in the Merensky Reef, Bushveld complex. J Petrol, 2000, 41: 545-561

66 Mungall J E, Andrews D R A, Cabri L J, et al. Partitioning of Cu,
$\mathrm{Ni}, \mathrm{Au}$, and platinum-group elements between monosulfide solid solution and sulfide melt under controlled oxygen and sulfur fugacities. Geochim Cosmochim Acta, 2005, 69: 4349-4360

67 Dewaele S, Muchez P, Hertogen J. Production of a matrix-matched standard for quantitative analysis of iron sulphides by laser ablation inductively coupled plasma-mass spectrometry by welding: A pilot study. Geol Belg, 2007, 10: 109-119

68 Danyushevsky L, Robinson P, Gilbert S, et al. Routine quantitative multi-element analysis of sulphide minerals by laser ablation ICP-MS: Standard development and consideration of matrix effects. Geochem Explor Environ Anal, 2011, 11: 51-60

69 Ding L, Yang G, Xia F, et al. A LA-ICP-MS sulphide calibration standard based on a chalcogenide glass. Mineral Mag, 2011, 75: 279-287

70 Perkins W T, Pearce N J G, Westgate J A. The development of laser ablation ICP-MS and calibration strategies: Examples from the analysis of trace elements in volcanic glass shards and sulfide minerals. Geostand Geoanal Res, 1997, 21: 175-190

71 Wilson S A, Ridley W I, Koenig A E. Development of sulfide calibration standards for the laser ablation inductively-coupled plasma mass spectrometry technique. J Anal At Spectrom, 2002, 17: 406-409

72 Gilbert S, Danyushevsky L, Robinson P, et al. A comparative study of five reference materials and the Lombard meteorite for the determination of the platinum-group elements and gold by LA-ICPMS. Geostand Geoanal Res, 2012: doi: 10.1111/j.1751-908X.2012. 00170.x

73 Wohlgemuth-Ueberwasser C, Ballhaus C, Berndt J, et al. Synthesis of PGE sulfide standards for laser ablation inductively coupled plasma mass spectrometry (LA-ICP-MS). Contrib Mineral Petrol, 2007, 154: 607-617

74 Sylvester P J, Cabri L J, Tubrett M N, et al. Synthesis and evaluation of a fused pyrrhotite standard reference material for platinum-group element and gold analysis by laser ablation ICP-MS. In: Tormanen T O T, Alapieti T T A, eds. Platinum-group elements from genesis to beneficiation and environmental impact. 10th International Platinum Symposium. Oulu, Finland, 2005

75 Alard O, Griffin W L, Lorand J P, et al. Non-chondritic distribution of the highly siderophile elements in mantle sulphides. Nature, 2000, 407: 891-894

76 Morgan J W, Horan M F, Walker R J, et al. Rheniumum concentration and isotope systematics in group IIAB iron meteorites. Geochim Cosmochim Acta, 1995, 59: 2331-2344

77 Bédard L P, Baker D R, Machado N. A new technique for the synthesis of geochemical reference samples for laser ablation-ICPMS analysis of zircons. Chem Geol, 1997, 138: 1-7

78 Klemme S, Prowatke S, Münker C, et al. Synthesis and preliminary characterisation of new silicate, phosphate and titanite reference glasses. Geostand Geoanal Res, 2008, 32: 39-54

79 Perkins W T, Fuge R, Pearce N J G. Quantitative analysis of trace elements in carbonates using laser ablation inductively coupled plasma mass spectrometry. J Anal At Spectrom, 1991, 6: 445-449

80 Fallon S J, McCulloch M T, van Woesik R, et al. Corals at their latitudinal limits: Laser ablation trace element systematics in Porites from Shirigai Bay, Japan. Earth Planet Sci Lett, 1999, 172: 221-238

81 Bellotto V R, Miekeley N. Improvements in calibration procedures for the quantitative determination of trace elements in carbonate material (mussel shells) by laser ablation ICP-MS. Fresenius J Anal Chem, 2000, 367: 635-640

82 Barats A, Pécheyran C, Amouroux D, et al. Matrix-matched quantitative analysis of trace-elements in calcium carbonate shells by laser-ablation ICP-MS: Application to the determination of daily scale profiles in scallop shell (Pecten maximus). Anal Bioanal Chem, 2007, 387: 1131-1140

83 Tanaka K, Takahashi Y, Shimizu H. Determination of rare earth element in carbonate using laser-ablation inductively-coupled plasma mass spectrometry: An examination of the influence of the matrix on laser-ablation inductively-coupled plasma mass spectrometry analysis. Anal Chim Acta, 2007, 583: 303-309 
84 Eggins S M, Shelley J M G. Compositional heterogeneity in NIST SRM 610-617 glasses. Geostand Geoanal Res, 2002, 26: 269-286

85 Jochum K P, Stoll B, Herwig K, et al. Validation of LA-ICP-MS trace element analysis of geological glasses using a new solid-state $193 \mathrm{~nm} \mathrm{Nd}$ :YAG laser and matrix-matched calibration. J Anal At Spectrom, 2007, 22: 112-121

$86 \mathrm{Hu} \mathrm{Z} \mathrm{C,} \mathrm{Liu} \mathrm{Y} \mathrm{S,} \mathrm{Chen} \mathrm{L,} \mathrm{et} \mathrm{al.} \mathrm{Contrasting} \mathrm{matrix} \mathrm{induced}$ elemental fractionation in NIST SRM and rock glasses during laser ablation ICP-MS analysis at high spatial resolution. J Anal At Spectrom, 2011, 26: 425-430

87 Gaboardi M, Humayun M. Elemental fractionation during LA-ICPMS analysis of silicate glasses: Implications for matrix-independent standardization. J Anal At Spectrom, 2009, 24: 1188-1197

88 Liu Y S, Gao S, Hu Z C, et al. Continental and oceanic crust recycling-induced melt-peridotite interactions in the Trans-North China Orogen: $\mathrm{U}-\mathrm{Pb}$ dating, $\mathrm{Hf}$ isotopes and trace elements in zircons of mantle xenoliths. J Petrol, 2010, 51: 537-571

$89 \mathrm{Hu}$ Z C, Gao S, Liu Y S, et al. Niobium and tantalum concentrations in NIST SRM 610 revisited. Geostand Geoanal Res, 2008, 32: $347-$ 360

90 Kent A J R, Jacobsen B, Peate D W, et al. Isotope dilution MC-ICPMS rare earth element analysis of geochemical reference materials NIST SRM 610, NIST SRM 612, NIST SRM 614, BHVO-2G, BHVO-2, BCR-2G, JB-2, WS-E, W-2, AGV-1 and AGV-2. Geostand Geoanal Res, 2004, 28: 417-429

91 Sylvester P J, Eggins S M. Analysis of Re, Au, Pd, Pt and Rh in NIST glass certified reference materials and natural basalt glasses by laser ablation ICP-MS. Geostand Geoanal Res, 1997, 21: 215-229

$92 \mathrm{Hu}$ Z C, Liu Y S, Li M, et al. Results for rarely determined elements in MPI-DING, USGS and NIST SRM glasses using laser ablation ICP-MS. Geostand Geoanal Res, 2009, 33: 319-335

93 Strnad L, Mihaljevic M, Sebek O. Laser ablation and solution ICPMS determination of rare earth elements in USGS BIR-1G, BHVO$2 \mathrm{G}$ and BCR-2G glass reference materials. Geostand Geoanal Res, 2005, 29: 303-314

$94 \mathrm{Hu}$ Z C, Gao S, Liu Y S, et al. Accurate determination of rare earth elements in USGS, NIST SRM, and MPI-DING glasses by excimer LA-ICP-MS at high spatial resolution. Spectrosc Lett, 2008, 41: 228-236

95 Jochum K P, Scholz D, Stoll B, et al. Accurate trace element analysis of speleothems and biogenic calcium carbonates by LAICP-MS. Chem Geol, 2012, 318-319: 31-44

96 Günther D, Heinrich C A. Comparison of the ablation behaviour of $266 \mathrm{~nm} \mathrm{Nd}$ : YAG and $193 \mathrm{~nm}$ ArF excimer lasers for LA-ICP-MS analysis. J Anal At Spectrom, 1999, 14: 1369-1374

97 Longerich H P, Günther D, Jackson S E. Elemental fractionation in laser ablation inductively coupled plasma mass spectrometry. Fresenius J Anal Chem, 1996, 355: 538-542

98 Míková J, Košler J, Longerich H P, et al. Fractionation of alkali elements during laser ablation ICP-MS analysis of silicate geological samples. J Anal At Spectrom, 2009, 24: 1244-1252

99 Kuhn H-R, Guillong M, Günther D. Size-related vaporisation and ionisation of laser-induced glass particles in the inductively coupled plasma. Anal Bioanal Chem, 2004, 378: 1069-1074

100 Košler J, Wiedenbeck M, Wirth R, et al. Chemical and phase composition of particles produced by laser ablation of silicate glass and zircon-implications for elemental fractionation during ICP-MS analysis. J Anal At Spectrom, 2005, 20: 402-409

101 Eggins S M, Kinsley L P J, Shelley J M G. Deposition and element fractionation processes during atmospheric pressure laser sampling for analysis by ICP-MS. Appl Surf Sci, 1998, 127-129: 278-286

102 Fryer B J, Jackson S E, Longerich H P. The design, operation and role of the laser-ablation microprobe coupled with an inductively coupled plasma-mass spectrometer (LAM-ICP-MS) in the earth sciences. Can Mineral, 1995, 33: 303-312

103 Kuhn H R, Günther D. Laser ablation-ICP-MS: Particle size dependent elemental composition studies on filter-collected and online measured aerosols from glass. J Anal At Spectrom, 2004, 19: $1158-1164$
104 Hu Z C, Liu Y S, Gao S, et al. A local aerosol extraction strategy for the determination of the aerosol composition in laser ablation inductively coupled plasma mass spectrometry. J Anal At Spectrom, 2008, 23: 1192-1203

105 Günther D, Hattendorf B. Solid sample analysis using laser ablation inductively coupled plasma mass spectrometry. Trends Anal Chem, 2005, 24: 255-265

106 Liu Y S, Hu Z C, Yuan H L, et al. Volume-optional and lowmemory (VOLM) chamber for laser ablation-ICP-MS: Application to the analyses of fiber. J Anal At Spectrom, 2007, 22: 582-585

107 Pisonero J, Fliegel D, Günther D. High efficiency aerosol dispersion cell for laser ablation-ICP-MS. J Anal At Spectrom, 2006, 21: 922931

108 Bleiner D, Günther D. Theoretical description and experimental observation of aerosol transport processes in laser ablation inductively coupled plasma mass spectrometry. J Anal At Spectrom, 2001, 16: 449-456

109 Mank A J G, Mason P R D. A critical assessment of laser ablation ICP-MS as an analytical tool for depth analysis in silica-based glass samples. J Anal At Spectrom, 1999, 14: 1143-1153

110 Horn I, Günther D. The influence of ablation carrier gasses $\mathrm{Ar}, \mathrm{He}$ and $\mathrm{Ne}$ on the particle size distribution and transport efficiencies of laser ablation-induced aerosols: implications for LA-ICP-MS. Appl Surf Sci, 2003, 207: 144-157

111 Košler J, Longerich H, Tubrett M. Effect of oxygen on laser-induced elemental fractionation in LA-ICP-MS analysis. Anal Bioanal Chem, 2002, 374: 251-254

112 Hirata T. Chemically assisted laser ablation ICP mass spectrometry. Anal Chem, 2003, 75: 228-233

113 Garcia C C, Lindner H, Niemax K. Laser ablation inductively coupled plasma mass spectrometry-current shortcomings, practical suggestions for improving performance, and experiments to guide future development. J Anal At Spectrom, 2009, 24: 14-26

114 Kroslakova I, Günther D. Elemental fractionation in laser ablation-inductively coupled plasma-mass spectrometry: Evidence for mass load induced matrix effects in the ICP during ablation of a silicate glass. J Anal At Spectrom, 2007, 22: 51-62

115 Koch J, Walle M, Pisonero J, et al. Performance characteristics of ultra-violet femtosecond laser ablation inductively coupled plasma mass spectrometry at $\sim 265$ and $\sim 200 \mathrm{~nm}$. J Anal At Spectrom, 2006, 21: 932-940

116 Zong K, Liu Y, Gao C, et al. In situ U-Pb dating and trace element analysis of zircons in thin sections of eclogite: Refining constraints on the ultra high-pressure metamorphism of the Sulu terrane, China. Chem Geol, 2010, 269: 237-251

117 Liu X M, Gao S, Diwu C R, et al. Simultaneous in-situ determination of $\mathrm{U}-\mathrm{Pb}$ age and trace elements in zircon by LA-ICPMS in $20 \mu \mathrm{m}$ spot size. Chin Sci Bull, 2007, 52: 1257-1264

118 Günther D A, Heinrich C. Enhanced sensitivity in laser ablationICP mass spectrometry using helium-argon mixtures as aerosol carrier. J Anal At Spectrom, 1999, 14: 1363-1368

119 Nesbitt R W, Hirata T, Butler I B, et al. UV laser ablation ICP-MS: Some applications in the earth sciences. Geostand Geoanal Res, 1997, 21: 231-243

120 Hu Z C, Gao S, Liu Y S, et al. Signal enhancement in laser ablation ICP-MS by addition of nitrogen in the central channel gas. J Anal At Spectrom, 2008, 23: 1093-1101

121 Durrant S F. Feasibility of improvement in analytical performance in laser ablation inductively coupled plasma-mass spectrometry (LA-ICP-MS) by addition of nitrogen to the argon plasma. Fresenius J Anal Chem, 1994, 349: 768-771

122 Luo Y, Gao S, Longerich H P, et al. The uncertainty budget of the multi-element analysis of glasses using LA-ICP-MS. J Anal At Spectrom, 2007, 22: 122-130

123 Cheatham M M, Sangrey W F, White W M. Sources of error in external calibration ICP-MS analysis of geological samples and an improved non-linear drift correction procedure. Spectrochim Acta Part B, 1993, 48: 487-506

124 Eggins S M, Woodhead J D, Kinsley L P J, et al. A simple method 
for the precise determination of $\geqslant 40$ trace elements in geological samples by ICPMS using enriched isotope internal standardisation. Chem Geol, 1997, 134: 311-326

125 Sinclair D J, Kinsley L P J, McCulloch M T. High resolution analysis of trace elements in corals by laser ablation ICP-MS. Geochim Cosmochim Acta, 1998, 62: 1889-1901

126 Gonzalez J J, Oropeza D D, Longerich H, et al. Rapid bulk analysis using femtosecond laser ablation inductively coupled plasma timeof-flight mass spectrometry. J Anal At Spectrom, 2012, 27: 14051412

127 O'Connor C, Landon M R, Sharp B L. Absorption coefficient modified pressed powders for calibration of laser ablation inductively coupled plasma mass spectrometry. J Anal At Spectrom, 2007, 22: 273-282

128 Arroyo L, Trejos T, Gardinali P R, et al. Optimization and validation of a laser ablation inductively coupled plasma mass spectrometry method for the routine analysis of soils and sediments. Spectrochim Acta Part B, 2009, 64: 16-25

129 Perkins W T, Pearce N J G, Jeffries T E. Laser ablation inductively coupled plasma mass-spectrometry-A new technique for the determination of trace and ultra-trace elements in silicates. Geochim Cosmochim Acta, 1993, 57: 475-482

130 Becker J S, Dietze H J. Determination of trace elements in geological samples by laser ablation inductively coupled plasma mass spectrometry. Fresenius J Anal Chem, 1999, 365: 429-434

131 Kurosawa M, Shima K, Ishii S, et al. Trace element analysis of fused whole-rock glasses by laser ablation-ICP-MS and PIXE. Geostand Geoanal Res, 2006, 30: 17-30

132 Fedorowich J S, Richards J P, Jain J C, et al. A rapid method for REE and trace-element analysis using laser sampling ICP-MS on direct fusion whole-rock glasses. Chem Geol, 1993, 106: 229-249

133 Reid J E, Horn I, Longerich H P, et al. Determination of Zr and Hf in a flux-free fusion of whole rock samples using Laser Ablation Inductively Coupled Plasma-Mass Spectrometry (LA-ICP-MS) with isotope dilution calibration. Geostand Geoanal Res, 1999, 23: 149155

134 Nehring F, Jacob D E, Barth M G, et al. Laser-ablation ICP-MS analysis of siliceous rock glasses fused on an iridium strip heater using $\mathrm{MgO}$ dilution. Microchimica Acta, 2008, 160: 153-163

135 Williams J G, Jarvis K E. Preliminary assessment of laser ablation inductively coupled plasma mass spectrometry for quantitative multi-element determination in silicates. J Anal At Spectrom, 1993, 8: $25-34$

136 Van Heuzen A A, Morsink J B W. Analysis of solids by laser ablation-inductively coupled plasma-mass spectrometry (LA-ICPMS)-II. Matching with a pressed pellet. Spectrochim Acta Part B, 1991, 46: 1819-1828

137 Sylvester P. Trace element analysis of fused whole rock glasses by laser ablation ICPMS. In: Sylvester P, ed. Laser-ablation-ICPMS in the Earth Sciences: Principles and Applications. Ontario: Mineralogical Association of Canada, 2001. 147-162

138 Konter J G, Hanan B B, Blichert-Toft J, et al. One hundred million years of mantle geochemical history suggest the retiring of mantle plumes is premature. Earth Planet Sci Lett, 2008, 275: 285-295

139 Zhu L-Y, Liu Y-S, Hu Z-C, et al. Quick and accurate LA-ICP-MS analyses of major and trace elements in basalt, coupled with glass fusion method by double iridium strip heater (in Chinese). Geochimica, 2011, 40: 407-417

140 Boulyga S F, Heumann K G. Direct determination of halogens in powdered geological and environmental samples using isotope dilution laser ablation ICP-MS. Int J Mass Spectrom, 2005, 242: 291-296

141 Mason P R D, Jarvis K E, Downes H, et al. Determination of incompatible trace elements in mantle clinopyroxenes by LA-ICPMS: A comparison of analytical performance with established techniques. Geostand Geoanal Res, 1999, 23: 157-172

$142 \mathrm{Hu}$ M Y, He H L, Zhan X C, et al. Matrix normalization for in situ multi element quantitative analysis of zircon in laser ablation inductively coupled plasmamass spectrometry (in Chinese). Chin J
Anal Chem, 2008, 36: 947-953

143 Mertz-Kraus R, Brachert T C, Jochum K P, et al. LA-ICP-MS analyses on coral growth increments reveal heavy winter rain in the Eastern Mediterranean at $9 \mathrm{Ma}$. Palaeogeogr Palaeoclimatol Palaeoecol, 2009, 273: 25-40

144 Munksgaard N C, Antwertinger Y, Parry D L. Laser ablation ICPMS analysis of Faviidae corals for environmental monitoring of a tropical estuary. Environ Chem, 2004, 1: 188-196

145 Strnad L, Ettler V, Mihaljevic M, et al. Determination of trace elements in calcite using solution and laser ablation ICP-MS: Calibration to NIST SRM glass and USGS MACS carbonate, and application to real landfill calcite. Geostand Geoanal Res, 2009, 33: $347-355$

$146 \mathrm{Xu} \mathrm{H} \mathrm{Z,} \mathrm{Hu} \mathrm{S} \mathrm{H,} \mathrm{Hu} \mathrm{Z} \mathrm{C,} \mathrm{et} \mathrm{al.} \mathrm{Determination} \mathrm{of} \mathrm{rare} \mathrm{earth} \mathrm{elements}$ in rich-co crust by $193 \mathrm{~nm}$ arf excimer laser ablation-inductively coupled plasma mass spectrometry (in Chinese). J Anal Sci, 2005, 21: $119-122$

147 Huelin S R, Longerich H P, Wilton D H C, et al. The determination of trace elements in Fe-Mn oxide coatings on pebbles using LA-ICP-MS. J Geochem Explor, 2006, 91: 110-124

148 Nadoll P, Koenig A E. LA-ICP-MS of magnetite: Methods and reference materials. J Anal At Spectrom, 2011, 26: 1872-1877

149 Donohue P H, Simonetti A, Neal C R. Chemical characterisation of natural ilmenite: A possible new reference material. Geostand Geoanal Res, 2012, 36: 61-73

150 Luvizotto G L, Zack T, Meyer H P, et al. Rutile crystals as potential trace element and isotope mineral standards for microanalysis. Chem Geol, 2009, 261: 346-369

151 Jorge A P d S, Enzweiler J, Shibuya E K, et al. Platinum-group elements and gold determination in NiS fire assay buttons by UV laser ablation ICP-MS. Geostand Geoanal Res, 1998, 22: 47-55

152 Resano M, Garcia-Ruiz E, McIntosh K S, et al. Laser ablationinductively coupled plasma-dynamic reaction cell-mass spectrometry for the determination of platinum group metals and gold in $\mathrm{NiS}$ buttons obtained by fire assay of platiniferous ores. J Anal At Spectrom, 2008, 23: 1599-1609

153 Piña R, Gervilla F, Barnes S J, et al. Distribution of platinum-group and chalcophile elements in the Aguablanca $\mathrm{Ni}-\mathrm{Cu}$ sulfide deposit (SW Spain): Evidence from a LA-ICP-MS study. Chem Geol, 2012, 302-303: 61-75

154 Norman M, Robinson P, Clark D. Major and trace element analysis of sulfide ores by laser-ablation ICP-MS, solution ICP-MS, and XRF: New data on international reference materials. Can Mineral, 2003, 41: 293-305

155 Cook N J, Ciobanu C L, Pring A, et al. Trace and minor elements in sphalerite: A LA-ICPMS study. Geochim Cosmochim Acta, 2009, 73: 4761-4791

156 Halter W E, Pettke T, Heinrich C A. The origin of $\mathrm{Cu} / \mathrm{Au}$ ratios in porphyry-type ore deposits. Science, 2002, 296: 1844-1846

157 Yuan J H, Zhan X C, Fan C Z, et al. Quantitative analysis of sulfide minerals by laser ablation-inductively coupled plasma-mass spectrometry using glass reference materials with matrix normalization plus sulfur internal standardization calibration. Chin J Anal Chem, 2012, 40: 201-207

158 Axelsson M D, Rodushkin I. Determination of major and trace elements in sphalerite using laser ablation double focusing sector field ICP-MS. J Geochem Explor, 2001, 72: 81-89

159 Heinrich C A, Pettke T, Halter W E, et al. Quantitative multielement analysis of minerals, fluid and melt inclusions by laserablation inductively-coupled-plasma mass-spectrometry. Geochim Cosmochim Acta, 2003, 67: 3473-3497

160 Pettke T, Oberli F, Audétat A, et al. Recent developments in element concentration and isotope ratio analysis of individual fluid inclusions by laser ablation single and multiple collector ICP-MS. Ore Geol Rev, 2012, 44: 10-38

161 Shepherd T J, Chenery S R. Laser ablation ICP-MS elemental analysis of individual fluid inclusions: An evaluation study. Geochim Cosmochim Acta, 1995, 59: 3997-4007

162 Moissette A, Shepherd T J, Chenery S R. Calibration strategies for 
the elemental analysis of individual aqueous fluid inclusions by laser ablation inductively coupled plasma mass spectrometry. J Anal At Spectrom, 1996, 11: 177-185

163 Ghazi A M, McCandless T E, Vanko D A, et al. New quantitative approach in trace elemental analysis of single fluid inclusions: Applications of laser ablation inductively coupled plasma mass spectrometry (LA-ICP-MS). J Anal At Spectrom, 1996, 11: 667-674

164 Shepherd T J, Ayora C, Cendon D I, et al. Quantitative solute analysis of single fluid inclusions in halite by LA-ICP-MS and cryoSEM-EDS: Complementary microbeam techniques. Eur J Mineral, 1998, 10: 1097-1108

165 Leisen M, Dubessy J, Boiron M-C, et al. Improvement of the determination of element concentrations in quartz-hosted fluid inclusions by LA-ICP-MS and Pitzer thermodynamic modeling of ice melting temperature. Geochim Cosmochim Acta, 2012, 90: 110 125

166 Allan M M, Yardley B W D, Forbes L J, et al. Validation of LA-ICP-MS fluid inclusion analysis with synthetic fluid inclusions. Am Mineral, 2005, 90: 1767-1775

167 Seo J H, Guillong M, Aerts M, et al. Microanalysis of S, Cl, and $\mathrm{Br}$ in fluid inclusions by LA-ICP-MS. Chem Geol, 2011, 284: 35-44

168 Leisen M, Boiron M C, Richard A, et al. Determination of $\mathrm{Cl}$ and $\mathrm{Br}$ concentrations in individual fluid inclusions by combining microthermometry and LA-ICPMS analysis: Implications for the origin of salinity in crustal fluids. Chem Geol, 2012, 330-331: 197-206

169 Taylor R P, Jackson S E, Longerich H P, et al. In situ trace-element analysis of individual silicate melt inclusions by laser ablation microprobe-inductively coupled plasma-mass spectrometry (LAMICP-MS). Geochim Cosmochim Acta, 1997, 61: 2559-2567

170 Kamenetsky V S, Eggins S M, Crawford A J, et al. Calcic melt inclusions in primitive olivine at $43^{\circ} \mathrm{N}$ MAR: Evidence for meltrock reaction/melting involving clinopyroxene-rich lithologies during MORB generation. Earth Planet Sci Lett, 1998, 160: 115-132

171 Spandler C J, Eggins S M, Arculus R J, et al. Using melt inclusions to determine parent-magma compositions of layered intrusions:
Application to the Greenhills Complex (New Zealand), a platinum group minerals-bearing, island-arc intrusion. Geology, 2000, 28: 991-994

172 Audétat A, Günther D, Heinrich C A. Magmatic-hydrothermal evolution in a fractionating granite: A microchemical study of the Sn-W-F-mineralized mole granite (Australia). Geochim Cosmochim Acta, 2000, 64: 3373-3393

173 Günther D, Hattendorf B, Audétat A. Multi-element analysis of melt and fluid inclusions with improved detection capabilities for $\mathrm{Ca}$ and Fe using laser ablation with a dynamic reaction cell ICP-MS. J Anal At Spectrom, 2001, 16: 1085-1090

174 Halter W E, Pettke T, Heinrich C A, et al. Major to trace element analysis of melt inclusions by laser-ablation ICP-MS: Methods of quantification. Chem Geol, 2002, 183: 63-86

175 Zajacz Z, Halter W. LA-ICPMS analyses of silicate melt inclusions in co-precipitated minerals: Quantification, data analysis and mineral/melt partitioning. Geochim Cosmochim Acta, 2007, 71: 10211040

176 Zajacz Z, Kovacs I, Szabo C, et al. Evolution of mafic alkaline melts crystallized in the uppermost lithospheric mantle: A melt inclusion study of olivine-clinopyroxenite xenoliths, northern Hungary. J Petrol, 2007, 48: 853-883

177 Severs M J, Beard J S, Fedele L, et al. Partitioning behavior of trace elements between dacitic melt and plagioclase, orthopyroxene, and clinopyroxene based on laser ablation ICPMS analysis of silicate melt inclusions. Geochim Cosmochim Acta, 2009, 73: 2123-2141

178 Guzmics T, Zajacz Z, Kodolanyi J, et al. LA-ICP-MS study of apatite- and $\mathrm{K}$ feldspar-hosted primary carbonatite melt inclusions in clinopyroxenite xenoliths from lamprophyres, Hungary: Implications for significance of carbonatite melts in the Earth's mantle. Geochim Cosmochim Acta, 2008, 72: 1864-1886

179 Zhang C L, Liu Y S, Gao S, et al. Chemical compositions of phenocryst-hosted melt inclusions from the Sihetun basalt: Implications for the magma evolution (in Chinese). Geochimica, 2011, 40: $109-125$

Open Access This article is distributed under the terms of the Creative Commons Attribution License which permits any use, distribution, and reproduction in any medium, provided the original author(s) and source are credited. 